\title{
Voltage Clamp Analysis of Membrane Currents in Larval Muscle Fibers of Drosophila: Alteration of Potassium Currents in Shaker Mutants ${ }^{1}$
}

\author{
CHUN-FANG WU ${ }^{2}$ AND FRANK N. HAUGLAND
}

Department of Biology and Department of Physiology and Biophysics, University of lowa, lowa City, lowa 52242

\begin{abstract}
The body wall muscles in Drosophila larvae are suitable for voltage clamp analysis of changes in membrane excitability caused by mutations. Both inward and outward ionic currents are present in these muscle fibers. The inward current is mediated by voltage-dependent $\mathrm{Ca}^{2+}$ channels. In $\mathrm{Ca}^{2+}$-free saline, the inward current is eliminated. The remaining outward $\mathrm{K}^{+}$currents consist of two distinct components, an early transient $I_{\mathrm{A}}$ and a delayed steady $I_{\mathrm{K}}$, which are separable by differences in the rate and voltage dependence of activation and inactivation. The steady-state and kinetic properties of the activation and inactivation processes of these two currents are analyzed. The results provide a basis for quantitative analysis of altered membrane currents in behavioral mutants of Drosophila.

Previous studies indicate that mutations in the Shaker (Sh) locus alter excitability in both nerve and muscle in Drosophila. Our results support the idea that the channels mediating $I_{\mathrm{A}}$ are molecularly distinct from those mediating $I_{\mathrm{K}}$. All $S h$ mutations studied specifically affect $I_{A}$ without changing the properties of the calcium current and $I_{K}$. In certain alleles $\left(S h^{\mathrm{kS133}}, S h^{102}\right.$, and $\left.S h^{M}\right) I_{\mathrm{A}}$ is eliminated, permitting detailed studies of $I_{K}$ in isolation of $I_{A}$.

Studies of the alleles that do not eliminate $I_{A}$ provide additional information of the channels. In one such allele, $S h^{5}$, voltage dependence of $I_{A}$ activation is shifted to more positive potentials. This is accompanied by a less pronounced shift in the voltage dependence of inactivation. These results suggest that $S h^{5}$ mutation affects the voltagesensitive mechanism of both activation and inactivation processes and that these two processes are not controlled by independent parts of the channel. Furthermore, the differential effects of these alleles on different excitable membranes imply that other genes take part in the control of $I_{A}$. The effects of $S^{5}$ on muscle depend on developmental stage. In larval muscle, $S h^{5}$ reduces the amplitude of $I_{A}$ because of the shift in the current-voltage (I-V) relation. In
\end{abstract}

Received July 9, 1984; Revised March 19, 1985;

Accepted March 19, 1985

${ }^{1}$ We thank Drs. B. Ganetzky, P. Getting, R. Hahin, R. Joyner, and C. Marchand for comments on the manuscript. We gratefully acknowledge the help of Dr. R. Joyner in instrumentation. This work was supported by United States Public Health Service Grants NS00675 and NS18500 and a grant from the Searle Scholars Program to C. -F. W. F. N. H. was supported by National Institute of Mental Health Training grant MH15172.

${ }^{2}$ To whom correspondence should be addressed, at Department of Biology, University of lowa, lowa City, IA 52242. contrast, in adult $S h^{5}$ muscles, $I_{A}$ is reported to be normal in amplitude but shows abnormally rapid inactivation (Salkoff, L., and R. Wyman (1981) Nature 293: 228-230). A different allele, $S h^{\text {rk0120 }}$, causes a clear defect in nerve excitability, but analysis of $I_{A}$ in $S h^{\text {rk0120 }}$ larval muscle reveals I-V relations, inactivation, and recovery from inactivation similar to those seen in normal fibers. We suggest a possible mechanism of combinations of multiple interacting genes participating in the control of potassium channels to account for the presence of a variety of potassium channels in different excitable membranes.

Information regarding the structural and functional mechanisms of macromolecular components in excitable membranes can be inferred from the specific effects caused by mutational perturbations. In Drosophila, neurophysiological analyses of several behavioral mutants indicate defects in membrane excitability (Ikeda and Kaplan, 1970; Siddiqi and Benzer, 1976; Jan et al., 1977; Wu et al., 1978; Ganetzky and Wu, 1982a). In certain cases, the defects have been attributed to altered ionic currents (Jan et al., 1977; Wu and Ganetzky, 1980; Salkoff and Wyman, 1981; Wu et al., 1983a). This genetic approach is particularly useful to obtain new information regarding ionic channels that are scarce in quantity and lack high affinity ligands to facilitate biochemical analysis.

Recently, the voltage clamp technique has been satisfactorily applied to investigate the effects of mutations on the membrane currents in both adult (Salkoff and Wyman, 1981, 1983) and larval (Wu et al., 1983a; Wu and Ganetzky, 1984) muscles. In the adult flight muscles, the inward current and different components of outward currents can be separated on the basis of their differences in developmental onset and mutational alteration (Salkoff and Wyman, 1983; Salkoff, 1983a). The body wall muscles of Drosophila larvae are developmentally distinct from the adult muscles, which arise de novo following histolysis of larval muscles during pupation. Knowledge concerning whether some properties of excitable membranes are controlled by different genes at different developmental stages can be gained by comparing data from these two sets of muscles.

Muscle fibers in the larval preparation (Jan and Jan, 1976) offer certain experimental advantages. The fibers in each segment form a regular pattern and are individually identifiable (Hewitt, 1914; Crossley, 1978). Since they are directly accessible to external bathing medium, problems in membrane potential measurements due to the series resistance and equilibration time for external solution changes are minimized. These relatively short fibers are electrically isolated from one another and each is virtually isopotential (Jan and Jan, 1976). They can readily be impaled by two microelectrodes to 
measure membrane currents under voltage clamp conditions (Wu et al., 1983a).

To provide a basis for quantitative analysis of altered membrane currents in behavioral mulants, we first report in detail the separation of various currents and their steady-state and kinetic properties in normal larvae. Drosophila larval muscles, like those of other arthropods (Fatt and Ginsborg, 1958; Werman et al., 1961; Yamamoto et al., 1981; Ashcroft and Stanfield, 1982), have voltage-dependent $\mathrm{Ca}^{2+}$ channels but do not have $\mathrm{Na}^{+}$channels. There are at least two outward $\mathrm{K}^{+}$currents: a rapid inactivating transient, similar to $I_{\mathrm{A}}$ described in molluscan neurons (Connor and Stevens, 1971b), and a delayed, sustained outward current, similar to the delayed rectifier, $I_{k}$ (Hodgkin and Huxley, 1952c).

Specific effects of the X-linked Shaker (Sh) mutations on larval muscle fibers are subsequently described. Sh mutants display vigorous leg-shaking behavior under ether anesthesia (Kaplan and Trout, 1969). At the larval neuromuscular junction, the Sh mutations have been associated with antidromic repetitive firing of motor axons resulting in prolonged transmitter release (Jan et al., 1977; Ganetzky and Wu, 1982b, 1983). Intracellular recordings from adult giant axons revealed abnormal action potentials with delayed repolarization (Tanouye et al., 1981). Recent voltage clamp studies of adult (Salkoff and Wyman, 1981; Salkoff, 1983b) and larval muscles (Wu et al., 1983a; Wu and Ganetzky, 1984) confirm the previous suggestion that Sh mutations affect potassium currents (Jan et al., 1977).

To examine the specificity of the mutant defects, a detailed study of the kinetic and steady-state properties of $I_{A}$ and $I_{K}$ were conducted in an array of available $S h$ alleles. Results indicate that $S h$ mutations affect $I_{\mathrm{A}}$ without altering $\mathrm{Ca}^{2+}$ current and $I_{\kappa}$. With certain $S h$ alleles, $I_{A}$ is completely abolished in larval muscles. Taking advantage of these mutants, we examined the activation and inactivation processes of $I_{K}$ in isolation in greater detail. In two alleles of $S h, I_{A}$ is altered but not eliminated. Analysis of properties of the remaining $I_{A}$ suggests interrelationships among some physiological parameters and regulation of $I_{A}$ function by genes besides $S h$.

Given the complexity of molecular assembly of some ionic channels (see, for example, Catterall, 1984; Mishina et al., 1985), mutations could disrupt a variety of mechanisms that determine the function of ion channels. Ultimately, understanding of the nature of Sh mutations correlated with the modified properties of $I_{A}$ may shed light upon the synthesis, regulation, and molecular gating mechanism of potassium channels in different excitable tissues. Preliminary accounts of some of the results reported here have appeared previously (Wu et al., 1983a; Wu and Ganetzky, 1984).

\section{Materials and Methods}

Strains. The wild-type strain, Canton-S of Drosophila melanogaster, was used to study the normal physiology of larval muscle fibers. Five different $S h$ alleles $\left(S h^{\kappa S 133}, S h^{102}, S h^{\mu}, S h^{5}\right.$, and $\left.S h^{r K 0120}\right)$ were examined. The mutant strains were obtained from the collection of Dr. S. Benzer at The California Institute of Technology. To confirm that the observed phenotypes are specifically derived from the $S h$ mutations, the $S h$ alleles were examined with several different Canton-S and Oregon-R backgrounds. The "Sh${ }^{\text {rko120 }}$ stocks" used in some previous reports have been shown to carry a second mutation at the eag locus (Ganetzky and Wu, 1983). This second site mutation was removed by recombination from the $S h^{r k 0120}$ stock used in the present study. An additional $S h^{5}$ stock was obtained from Dr. L. Salkoff (1983b) which yielded results consistent with data from the other $S h^{5}$ stocks.

Preparations and salines. The ventral lateral longitudinal fibers of mature third instar larvae were used for all experiments described. The larval preparation is identical to that previously described by Jan and Jan (1976) The temperature of the preparation was controlled by a Peltier junction microscope stage (Cambion Thermionic Corp., Cambridge, MA) and monitored by a thermistor (models ICT-4 and BAT-4, Bailey Instruments, Saddle Brook, $\mathrm{NJ}$ ) placed within $0.5 \mathrm{~mm}$ of the preparation in solution. The saline compositions for different experiments were modified from the standard physiological saline (Jan and Jan, 1976) containing $128 \mathrm{mM} \mathrm{NaCl}, 2 \mathrm{mM} \mathrm{KCl}$ $4 \mathrm{mM} \mathrm{MgCl}_{2}, 1.8 \mathrm{mM} \mathrm{CaCl}_{2}, 35.5 \mathrm{~mm}$ sucrose, buffered at $\mathrm{pH} 7.1$ with $5 \mathrm{~mm}$ $N$-2-hydroxyethyl- $N^{\prime}$-1-ethanesulfonic acid (HEPES).

For characterization of outward currents, the inward $\mathrm{Ca}^{2+}$ current was eliminated by the use of saline containing $0 \mathrm{~mm} \mathrm{CaCl}, 0.5 \mathrm{~mm}$ EGTA. Excess $\mathrm{MgCl}_{2}(14 \mathrm{mM}$ ) was added to stabilize the membrane (Salkoff and Wyman, 1981: Yamamoto et al., 1981). As in other species (Yamamoto et al., 1981, Hahin and Campbell, 1983), the presence of high concentration of $\mathrm{Mg}^{2+}$ circumvents the problems of muscle surface potential change and membrane leakage increase caused by $\mathrm{Ca}^{2+}$.free solution. To block $\mathrm{K}^{+}$channels, 5 to $10 \mathrm{~mm}$ tetraethylammonium (TEA) (Eastman, Rochester, NY) was added to the bathing solution. In the studies of the voltage-dependent channels mediating the inward currents, $\mathrm{SrCl}_{2}(10 \mathrm{~mm})$ was substituted for $\mathrm{CaCl}_{2}$ to minimize muscle contractions evoked by $\mathrm{Ca}^{2+}$ influx. The physiological effects of the slight changes in osmolarity or ionic strength caused by the additional solutes described above were expected to be within experimental variation (Jan and Jan, 1976), and no special effort was made to adjust for these changes. In some experiments (Fig. 7), the $\mathrm{K}^{+}$concentration was greatly increased (from 2 to $30 \mathrm{~mm}$ ). This was achieved by substitution of $\mathrm{KCl}$ for $\mathrm{NaCl}$.

Physiological recordings. The glass microelectrode used for the application of current was filled with $2 \mathrm{M}$ potassium citrate and the voltage recording electrode was filled with 2 to $3 \mathrm{M} \mathrm{KCl}$. The tip resistance of these microelectrodes usually ranged between 20 and 30 megohms, and in many experiments the resistance was reduced to a range between 10 and 15 megohms by bevelling according to methods described previously (Ogden et al., 1978). The current electrode was positioned near the middle of the muscle fiber and the voltage electrode was about 50 to $100 \mu \mathrm{m}$ apart from it. To minimize capacity coupling between the two electrodes, both electrode assemblies were electrically shielded to expose only the last $1 \mathrm{~cm}$ of the microelectrodes and mounted on the micromanipulators such that the angle between the two electrodes was $60^{\circ}$ or more.

The voltage clamp circuitry was similar to that used by previous investigators (Connor and Stevens, 1971a), except for the use of a high voltage operational amplifier (model AM-303B, Datel Systems, Inc., Canton, MA) as the source of the applied current. The membrane voltage and the signal from the virtual ground were displayed on a storage oscilloscope (Tektronix D13). Photographs of oscilloscope traces were taken and a chart recorder (Brush model 2200, Gould Inc., Cleveland, $\mathrm{OH}$ ) was used to keep continuous records of the relatively slow $I_{k}$. Measurements requiring a high precision were obtained from the digital readout of a digital oscilloscope equipped with magnetic disks for data slorage (model 4094, Nicolel Instrument Corp. Madison, WI), which was also interfaced to produce hard copies of the voltage and current traces on an X-Y plotter

Previous analysis (Jan and Jan, 1976) showed that these relatively short (about $400 \times 80 \times 25 \mu \mathrm{m}$ ) larval fibers are virtually isopotential. Calculations based on the short cable model (Weidmann, 1952) using the dimension of the fibers and the maximum active membrane conductance encountered in our experiments indicate that the deviation from isopotentiality was less than $10 \%$ throughout the fiber over the range of clamping potential used $(-100$ to $+30 \mathrm{mV}$ ).

Relatively low series resistance was expected because larval muscle fibers are free from the thick envelope of connective tissue and are highly accessible to drug agents in the bath solution. The series resistance was estimated by the initial step change in membrane potential preceding the exponential charging phase caused by application of a current step. The value was $54.1 \pm 24.2 \mathrm{kilohms}$ or $24.6 \pm 8.9 \mathrm{hm} \cdot \mathrm{cm}^{2}$ (mean $\pm \mathrm{SD}$ ) for the fibers $(n=10)$ tested. No compensation for the series resistance was attempted because the total membrane current in our study was generally within $\pm 100 \mathrm{nA}$. Error in membrane potential measurements due to the series resistance was therefore within the range of $5.4 \mathrm{mV}$ even in the extreme cases when the membrane was strongly depolarized $(V \geq+30 \mathrm{mV}$ ).

Step changes in membrane potential reached the steady level and mem. brane capacity currents settled within $2 \mathrm{msec}$ under optimal conditions and generally within $5 \mathrm{msec}$. The membrane voltage control was adequate for the membrane currents reported here as judged by the absence of "notches" in the membrane current traces and the lack of abrupt jumps in the currentvoltage relations (Taylor et al., 1960) for the inward current responsible for the regenerative action potential in larval muscles.

All fibers examined had a linear current-voltage relationship over the range -35 to $-70 \mathrm{mV}$. We assumed this to be a leakage conductance the value of which was independent of voltage. The stability of the leakage conductance was checked by hyperpolarizing or weak depolarizing voltage steps applied frequently throughout the course of an experiment. For stronger depolarizations the leakage current was extrapolated by using the calculated leakage conductance and subtracted from the total current to give the net active current.

Anatomical observations. The surface area of the identified fibers was estimated using scanning electron micrographs of mature third instar larvae dissected to expose the ventral longitudinal muscles. Computations of the 
surface areas of fibers were estimated according to the method of Jan and Jan (1976). This method neglects membrane invaginations, which would lead to underestimation of the actual cell membrane area but does allow for standardization and comparison of current density between fibers of different sizes. Since individual muscle fibers are readily identifiable and the mature third instar larvae used in these experiments were of rather uniform size, the surface area of each identified fiber was estimated without repeated individual measurements.

\section{Results}

\section{Normal membrane currents}

Passive membrane properties. The passive membrane properties of normal larval muscle fibers were determined under voltage clamp conditions, and the results are summarized in Table I. The specific membrane resistivity $\left(R_{\mathrm{m}}\right)$ was estimated by the leakage conductance adjusted for the surface area of the muscle fiber. Among 214 normal fibers included in this report, the mean $R_{\mathrm{m}}$ was 2.03 kilohm. $\mathrm{cm}^{2}$ and the maximum $R_{\mathrm{m}}$ was $5.6 \mathrm{kilohm} \cdot \mathrm{cm}^{2}$. The distribution was skewed to the lower values, which is attributable to the increased leakage introduced by microelectrode penetration.

To cstimate the specific membrane capacitance $\left(C_{m}\right)$, a triangular wave was used as the voltage command signal (Serrano, 1982) The membrane capacitance current $I_{\mathrm{c}}$ is determined by

$$
I_{c}=c_{m} \frac{d V}{d t}
$$

where $c_{m}$ is the membrane capacitance and $V$ is the membrane potential. The change in slope in the triangular waveform should induce a jump in $I_{c}$ and, hence, in the total membrane current of an absolute value of $2 c_{m} \frac{d V}{d t}$, where $\frac{d V}{d t}$ represents the slope of the rising phase of the triangular wave. The average value of $C_{m}$ computed from the cell surface area and $c_{m}$ thus cetermined was $7.1 \mu \mathrm{F} / \mathrm{cm}^{2}$. Our estimates of $C_{\mathrm{m}}$ and $R_{\mathrm{m}}$ are in general agreement with the previously reported values determined under current clarnp conditions (Jan and Jan, 1976).

Inward currents. Previous studies (Suzuki and Kano, 1977) sug gest that $\mathrm{Ca}^{2+}$ channels mediate the inward current in Drosophila larval muscles. Direct measurements of $\mathrm{Ca}^{2+}$ currents were difficult in these supercontracting muscles (Osborne, 1967) because the $\mathrm{Ca}^{2+}$ influx elicited strong contractions which immediately damaged the doubly impaled muscle fibers. When $\mathrm{Sr}^{2+}(10 \mathrm{~mm})$ was substituted for $\mathrm{Ca}^{2+}$, this probem was minimized. Thus, as an initial characterization of the $\mathrm{Ca}^{2+}$ channels in Drosophila larval muscles, we measured the voltage dependency of $\mathrm{Sr}^{2+}$ current, as has been studied previously in other preparations (Hagiwara, 1973; Hagiwara and Byerly, 1981).

Step depolarization from a holding potential $\left(V_{H}\right)$ of $-50 \mathrm{mV}$ to a level above $-30 \mathrm{mV}$ elicited an inward current which peaked rapidly and then decayed to a steady-state value. Both the rise and decay of the inward current became more rapid with increasing amplitude of depolarization steps. Pooled current-voltage (I-V) relations from four different fibers indicate that the net inward current reached a maximum at about $-5 \mathrm{mV}$ with a peak inward current density of $47.5 \pm 26 \mu \mathrm{A} / \mathrm{cm}^{2}$ (mean $\pm \mathrm{SD}$ ).

\section{TABLE}

Passive membrane properties of normal and Sh larval muscle fibers

The mean and SD of the specific membrane resistance $\left(A_{\mathrm{m}}\right)$ and the specific membrane capacitance $\left(C_{m}\right)$ are shown. The number of fibers used to determine each value is given in parentheses.

\begin{tabular}{ccc}
\hline & \multicolumn{1}{c}{$R_{\mathrm{m}}$} & \multicolumn{1}{c}{$\mathrm{C}_{\mathrm{m}}$} \\
\hline & $\mathrm{kilohm} \cdot \mathrm{cm}^{2}$ & $\mu F / \mathrm{cm}^{2}$ \\
Normal & $2.03 \pm 1.1(214)$ & $7.1 \pm 2.3(9)$ \\
Sh & $1.91 \pm 1.1(129)$ & $8.8 \pm 2.7(14)$ \\
\hline
\end{tabular}

Outward currents. We have studied the outward currents in greater detail because several mutations in Drosophila are known to affect the outward $\mathrm{K}^{+}$currents in larval muscles (Wu et al, 1983a; Wu and Ganetzky, 1984). Elimination of the inward $\mathrm{Ca}^{2+}$ current facilitated the analysis of outward $\mathrm{K}^{+}$currents and could be achieved by the use of saline containing $0 \mathrm{mM} \mathrm{Ca}^{2+}$ and $0.5 \mathrm{mM}$ EGTA (see "Materials and Methods"). Muscular contractions also ceased within a few seconds after substitution of physiological saline by the $\mathrm{Ca}^{2+}$. free saline. In this saline, the preparation could be maintained in good condition for at least $2 \mathrm{hr}$ at 5 to $15^{\circ} \mathrm{C}$, as evidenced by a negligible rundown of the active currents.

The lower traces in Figure 1A represent the currents recorded in response to step depolarizations (Fig. $1 A$, upper traces) from a holding potential of $V_{H}=-50 \mathrm{mV}$ in the $\mathrm{Ca}^{2+}$-free saline at $6^{\circ} \mathrm{C}$. Depolarization above $-30 \mathrm{mV}$ elicited a transient outward current which rose to a peak and then inactivated. With stronger depolarization, a delayed component also appeared. This component rose more slowly to a plateau without evidence of inactivation for these short pulses ( $\leq 420 \mathrm{msec}$ ).

Figure $1 B$ shows the $\mathrm{I}-\mathrm{V}$ relations of the outward currents at the peak of the transient and the end of depolarizing pulse at $6^{\circ} \mathrm{C}$ for the same cell of Figure $1 A$. The $\mathrm{IV}$ plot reflects the difference in the voltage dependence of the two components. The transient component was activated at less depolarized levels as compared with the delayed component. Similar I-V relations of the outward currents have been observed at all other temperatures examined (refer to Figs. 5 and 11 for data of $15^{\circ} \mathrm{C}$ ).

Since the transient current decayed rapidly during depolarizing pulses, we examined the currents in the same cell with $V_{H}=-25$ $\mathrm{mV}$ and obtained results strikingly different from those with $V_{H}=$ $-50 \mathrm{mV}$. The transient phase was virtually completely inactivated (Fig. 1C).

Thus, there appear to be two distinct outward currents which exhibit different voltage sensitivities and kinetic properties. The characteristics of these two components are similar to the $\mathrm{K}^{+}$ currents $I_{A}$ and $l_{K}$ described in molluscan neurons (Connor and Stevens, $197(\mathrm{a}, \mathrm{b})$ as well as in adult Drosophila flight muscles (Salkoff and Wyman, 1983). Indeed, both of these components were sensitive to the $\mathrm{K}^{+}$channel blocker TEA. Within seconds after adding $10 \mathrm{~mm}$ TEA to the bath, the transient component declined to $33 \%$ and the delayed component declined to $30 \%$ of control values. Hereafter we will refer to the transient outward current as $/ \mathrm{A}$ and the delayed outward current as $/ \mathrm{K}$

The I-V relations of outward currents with $V_{H}=-25 \mathrm{mV}$ (Fig. 1D) confirms that the remaining active currents have properties expected for $I_{\mathrm{K}}$. The steady-state currents are similar to those with $V_{H}=-50$ $m V$ (cf. solid symbols in Fig. $1, B$ and $D$ ), whereas at the time that peak $I_{\mathrm{A}}$ is observed with $V_{H}=-50 \mathrm{mV}$, only the rise of $I_{\mathrm{K}}$ is detected (cf. open symbols in Fig. 1, $B$ and $D$ ). Therefore, $I_{\mathrm{A}}$ and $I_{\mathrm{K}}$ are indeed separable components. (The amplitude of the $I_{\mathrm{K}}$ plateau in Fig. $1 D$ is smaller due to a partial inactivation of $I_{\mathrm{K}}$ at $V_{\mathrm{H}}=-25 \mathrm{mV}$; see Fig. 10.)

Activation and inactivation of $l_{A}$. It has been suggested that changes in voltage dependence of $I_{A}$ inactivation occur in certain eag (Wu and Ganetzy, 1984) and Sh (see below) mutants. We thus characterized the normal steady-state inactivation of $I_{\mathrm{A}}$ over a wide range of holding potentials, $V_{H}$.

Transient outward current $\left(I_{A}\right)$ was evoked at various holding potentials $\left(V_{H}\right)$ by test pulses to either -10 or $+10 \mathrm{mV}$ (cf. Fig. $12 \mathrm{~A}$ for the experimental paradigm). The peak $I_{\mathrm{A}}$ was normalized and plotted as a function of $V_{H}$. Figure 2 represents the pooled data from scveral fibers of different larvae illustrating the steady-state inactivation at 10 to $15^{\circ} \mathrm{C}$. It can be seen that, irrespective of the amplitude of test pulses (to $-10 \mathrm{mV}$, Fig. 2, open symbols, or to $+10 \mathrm{mV}$, Fig. 2 , solid symbols), the data can be described by the empirical function (continuous curve in Fig. 2):

$$
h_{\mathrm{A}}=1 /\left[1+\exp \left(\frac{V+40}{4.5}\right)\right]
$$


A
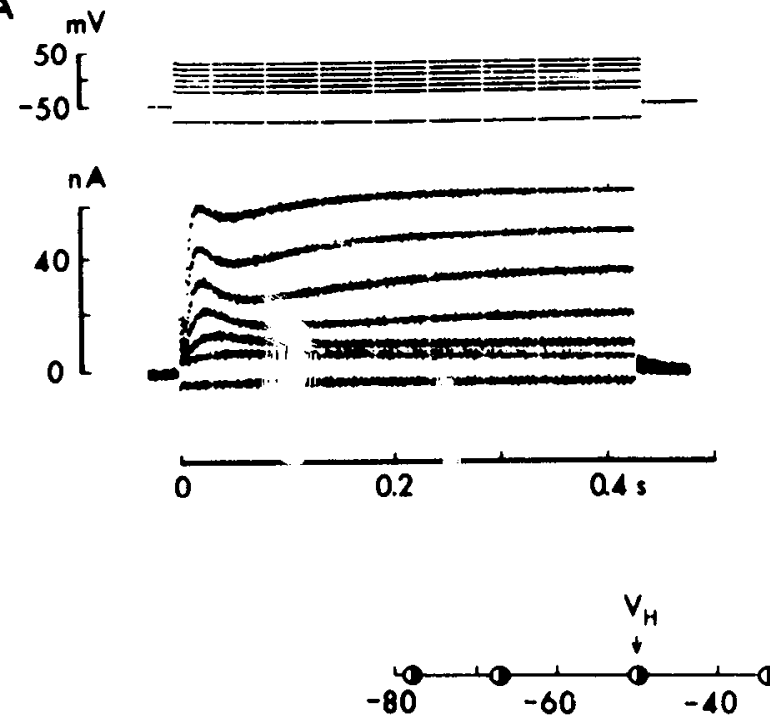

C
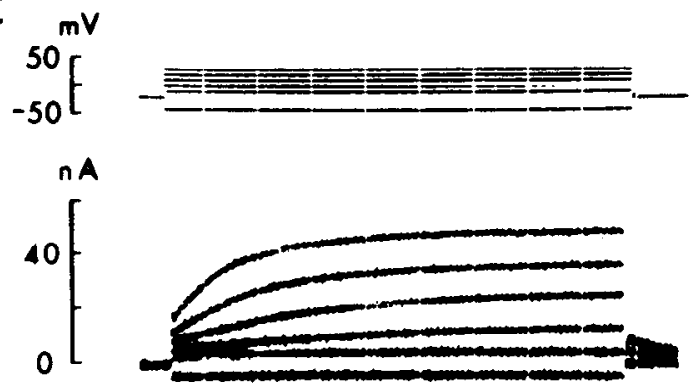

0

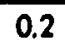

0.2

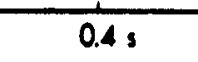

B

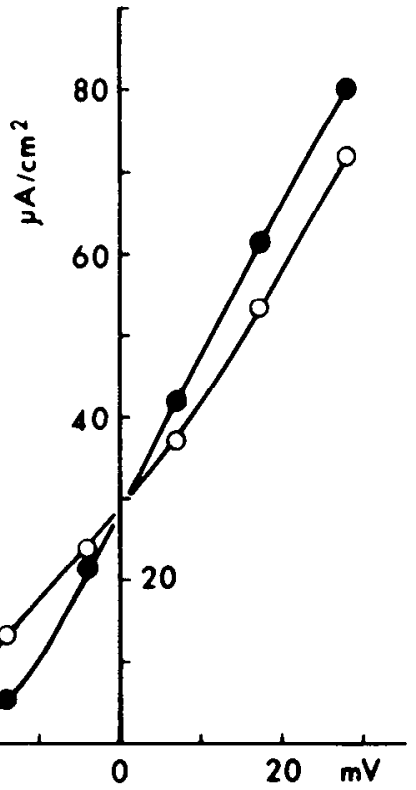

Figure 1. Membrane currents recorded from a normal fiber at $6^{\circ} \mathrm{C}$ Inward currents were eliminated by using $\mathrm{Ca}^{2+}$-free saline in experiments shown in this and all subsequent figures. $A$, Superimposed traces of total membrane currents (lower part) elicited by various voltage steps (upper part) from a holding potential $\left(V_{H}\right)$ of $-50 \mathrm{mV}$. Upward deflections indicate depolarizations or outward currents. Note that depolarizing steps positive to $-30 \mathrm{mV}$ elicited a transient outward current (/A) which inactivated rapidly. Depolarizing steps to more positive levels activated a delayed but sustained component $\left(V_{K}\right)$ in addition to the transient $l_{\mathrm{A}}$. See the text for the nomenclature. $B$, Current-voltage $(I-V)$ relation at $V_{H}=-50 \mathrm{mV}$. After correction for linear leakage currents, the amplitude of active currents at the peak of $I_{A}(O)$ and the end of the depolarizing pulse (O) are plotted against the membrane potential. $C$, Superimposed traces of total membrane currents and voltage steps from $V_{H}=-25 \mathrm{mV}$. Note that the transient $I_{\mathrm{A}}$ is absent. $D, \mathrm{I}-\mathrm{V}$ relation for the remaining active currents at $V_{H}=-25 \mathrm{mV}$. At $20 \mathrm{msec}$ after the onset of depolarizing pulses (near the peak of $I_{A}$ in $A$ ), only the rise of $I_{k}$ was detected $(O)$. The measurements at the end of pulses (O) represent steady-state $I_{k}$.

where $h_{A}$ represents the fraction of the uninactivated $I_{A}$ and $V$ is the potential (in millivolts) at which the membrane is held. This equation is of a form similar to that used by Hodgkin and Huxley (1952b) for their description of $\mathrm{Na}$ inactivation, which has been subsequently used to quantify inactivation of $I_{A}$ in other preparations (Neher, 1971; Hagiwara et al., 1981). Equation 2 specifies the $50 \%$ level of $I_{A}$ inactivation, i.e., $-40 \mathrm{mV}$, and the steepness of its voltage dependence about this midpoint, e.g., a positive or negative deviation of $4.5 \mathrm{mV}$ from $-40 \mathrm{mV}$ will change the level of inactivation to $1 /(1+$ e) or $1 /\left(1+e^{-1}\right)$, respectively. It should be noted that the larval muscle fibers normally have a resting potential of about $-50 \mathrm{mV}$ (Jan and Jan, 1976; C.-F. Wu, unpublished data). This would correspond to a resting inactivation of $I_{\mathrm{A}}$ of approximately $15 \%$.

To characterize the kinetic properties of $I_{\mathrm{A}}$, we examined the time course of $I_{A}$ activation and inactivation following step depolarizations. From the appearance of the traces shown in Figure $1 A$, the qualitative conclusion may be drawn that both activation and inactivation (the rising phase and falling phase) of $I_{A}$ occur more rapidly with stronger depolarizations. At $6^{\circ} \mathrm{C}$ the time to peak $I_{A}$ was $35 \mathrm{msec}$ at -15 $\mathrm{mV}, 25 \mathrm{msec}$ at $+5 \mathrm{mV}$, and $18 \mathrm{msec}$ at $+25 \mathrm{mV}$.

We limited our analysis of the kinetics of $I_{A}$ inactivation to depolarizations below the level where the rise of $I_{K}$ significantly overlaps the decay of $I_{\mathrm{A}}$. Traces similar to those with depolarizing pulses $<$ $-5 \mathrm{mV}$ shown in Figure $1 \mathrm{~A}$ were analyzed in semilogarithmic plots.
The initial phase of $/_{A}$ decay can be approximated by first-order kinetics, but the later phase deviates trom a first-order decay. The deviation became more pronounced with stronger depolarizations. This slower component may be accounted for by the slow rise of a small but detectable $I_{\mathrm{K}}$ at these depolarized levels (cf. Figs. 1 and 6).

The time constant of the initial decay, $\tau_{A}$, obtained by this method is shown as a function of voltage in Figure $3 A$, which allows the quantitative comparison with mutant data (cf. Fig. $3 B$ ). It is evident that $I_{A}$ decays more rapidly with stronger depolarizations. Data from three different temperature ranges indicate that $\tau_{\mathrm{A}}$ becomes faster at higher temperature with a $Q_{10}$ of about 2 over the range of 5 to $15^{\circ} \mathrm{C}$ (Fig. 3A).

Time course of $I_{A}$ recovery from inactivation. To gain knowledge about the reversibility of $I_{A}$ inactivation, we investigated the time course of $I_{A}$ recovery at $V=-50 \mathrm{mV}$, the normal resting potential, from inactivation induced by a conditioning pulse to $-10 \mathrm{mV}$. The membrane was first depolarized to $-10 \mathrm{mV}$ and then repolarized to $-50 \mathrm{mV}$ for various intervals before a brief test pulse (to $-10 \mathrm{mV}$ ) was applied. The inset of Figure 4 shows results obtained from two such experiments at $15^{\circ} \mathrm{C}$. It can be seen that the $I_{A}$ was rapidly inactivated by the conditioning pulses and that $I_{\mathrm{A}}$ recovery (at -50 $\mathrm{mV}$ ) is a much slower process.

Figure 4 represents pooled data at $15^{\circ} \mathrm{C}$ from a number of cells. 
Note that the peak $I_{\mathrm{A}}$ was normalized to allow comparison. The recovery time course could not be fitted by a simple first-order kinetics. The continuous lines in Figure 4 were drawn according to the sum of two exponentials

$$
Y=A\left(1-e^{-t / \tau_{1}}\right)+B\left(1-e^{-t / \tau_{2}}\right)
$$

where $\tau_{1}=75 \mathrm{msec}$ and $\tau_{2}=900 \mathrm{msec}$ and $A$ and $B$ are proportionality constants, which vary with the duration of conditioning pulses. Thus, the observed time course may reflect two different

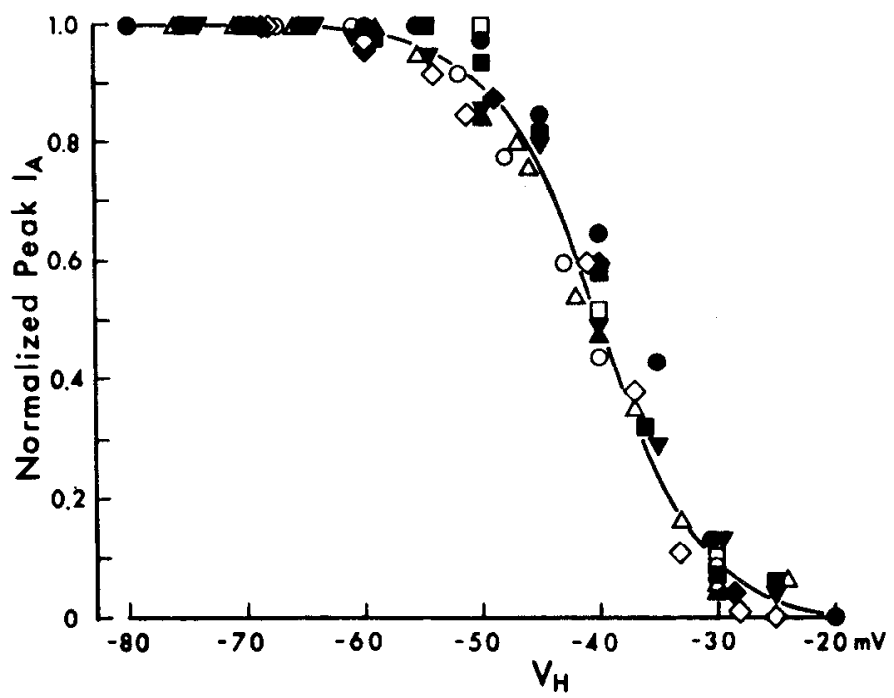

Figure 2. Effect of $V_{H}$ on the amplitude of $I_{A}$ in normal fibers. Pooled data are shown from four fibers with test pulses to $-10 \mathrm{mV}$ (open symbols) and five fibers to $+10 \mathrm{mV}$ (solid symbo/s), 11.5 to $15^{\circ} \mathrm{C}$ (cf. Fig. $12 \mathrm{~A}$ for examples of experimental records). Peak amplitudes of $I_{\mathrm{A}}$ are normalized and plotted as a function of $V_{H}$. The continuous curve is calculated from equation 2 in the text. steps in the reversible process of inactivation. The recovery from inactivation was more rapid with shorter conditioning pulses. The proportionality of the two components was $A=0.80$ and $B=0.20$ for $50 \mathrm{msec}$ conditioning duration and $A=0.45$ and $B=0.55$ for 350 msec duration.

\section{Isolation of $I_{K}$ in Sh mutants}

Passive membrane properties in Sh fibers. The passive membrane properties of larval muscle fibers of the Sh mutants were studied by the voltage clamp methods described above. Results obtained from the five different Sh alleles (see "Materials and Methods") showed no significant differences and data were combined and summarized in Table I. The average value of specific membrane resistance, $R_{\mathrm{m}}$, derived from the leakage conductance was 1.91 kilohm. $\mathrm{cm}^{2}$. As in normal tibers, the distribution was skewed toward lower values and the apparent upper limit was $4.9 \mathrm{kilohm} \cdot \mathrm{cm}^{2}$. The specific membrane capacitance, $C_{m}$, was $8.8 \mu \mathrm{F} / \mathrm{cm}^{2}$. These values are in close agreement with those of normal fibers, indicating no abnormality in the passive properties of Sh muscle fibers.

Inward current in Sh muscle fibers. It is important to determine whether Sh mutations specifically affect the outward current and leave the inward current intact. As in normal larvae, the inward current in Sh larvae was measured in $\mathrm{Ca}^{2+}$-free saline containing 10 $\mathrm{mM} \mathrm{Sr}{ }^{2+}$. Results similar to those of normal fibers were obtained. The I-V relation of the inward current and its time course appeared normal. The voltage at which inward currents were first detected (above $-30 \mathrm{mV}$ ) and peak amplitude of the inward $\mathrm{Sr}^{2+}$ current $\left(46.5 \pm 25 \mu \mathrm{A} / \mathrm{cm}^{2}\right.$, mean $\pm \mathrm{SD}$, at $\left.-5 \mathrm{mV}, n=4\right)$ were not significantly different from normal $\left(47.5 \pm 26 \mu \mathrm{A} / \mathrm{cm}^{2}\right)$.

Outward currents in Sh muscle fibers. The outward currents in Sh muscle fibers were studied in the same types of experiments described above for normal fibers. Among the five alleles examined, $S h^{K S 133}, S h^{M}$, and $S h^{102}$ apparently caused a loss of the transient outward current $I_{A}$ in the larval muscle membrane (Fig. 5). In contrast, $I_{A}$ was not completely abolished in the larval muscle of the other two alleles, $S h^{5}$ and $S h^{\text {rk0120 }}$, suggesting a difference in the nature of the
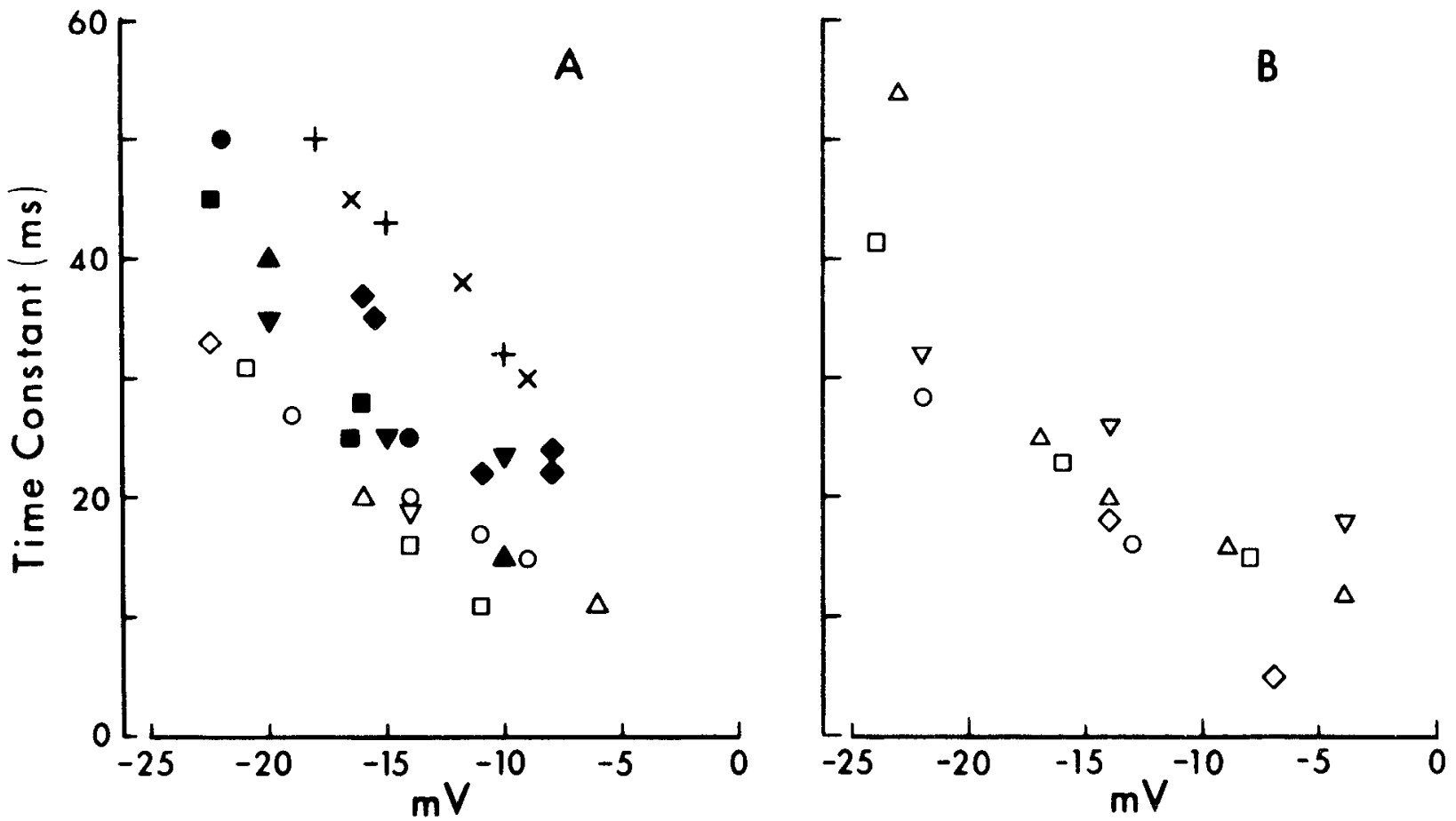

Figure 3. Kinetics of $I_{A}$ inactivation. A, Normal fibers. The time constant $\tau_{A}$ of the decay phase of $I_{A}$ elicited by voltage steps to various potentials from $V_{H}=-50 \mathrm{mV}$ was determined (see the text). The plot shows $\tau_{A}$ as a function of voltage. Pooled data from different cells (represented by individual symbols) at different temperature ranges were used: 6 to $8^{\circ} \mathrm{C}$ (crosses), 10 to $12^{\circ} \mathrm{C}$ (solid symbols), and 14 to $15^{\circ} \mathrm{C}$ (open symbo/s). $B$, Pouled dala from five $\mathrm{Sh}^{\prime \kappa 0120}$ fibers at $15^{\circ} \mathrm{C}$. Results are similar to those of normal fibers at this temperature. 


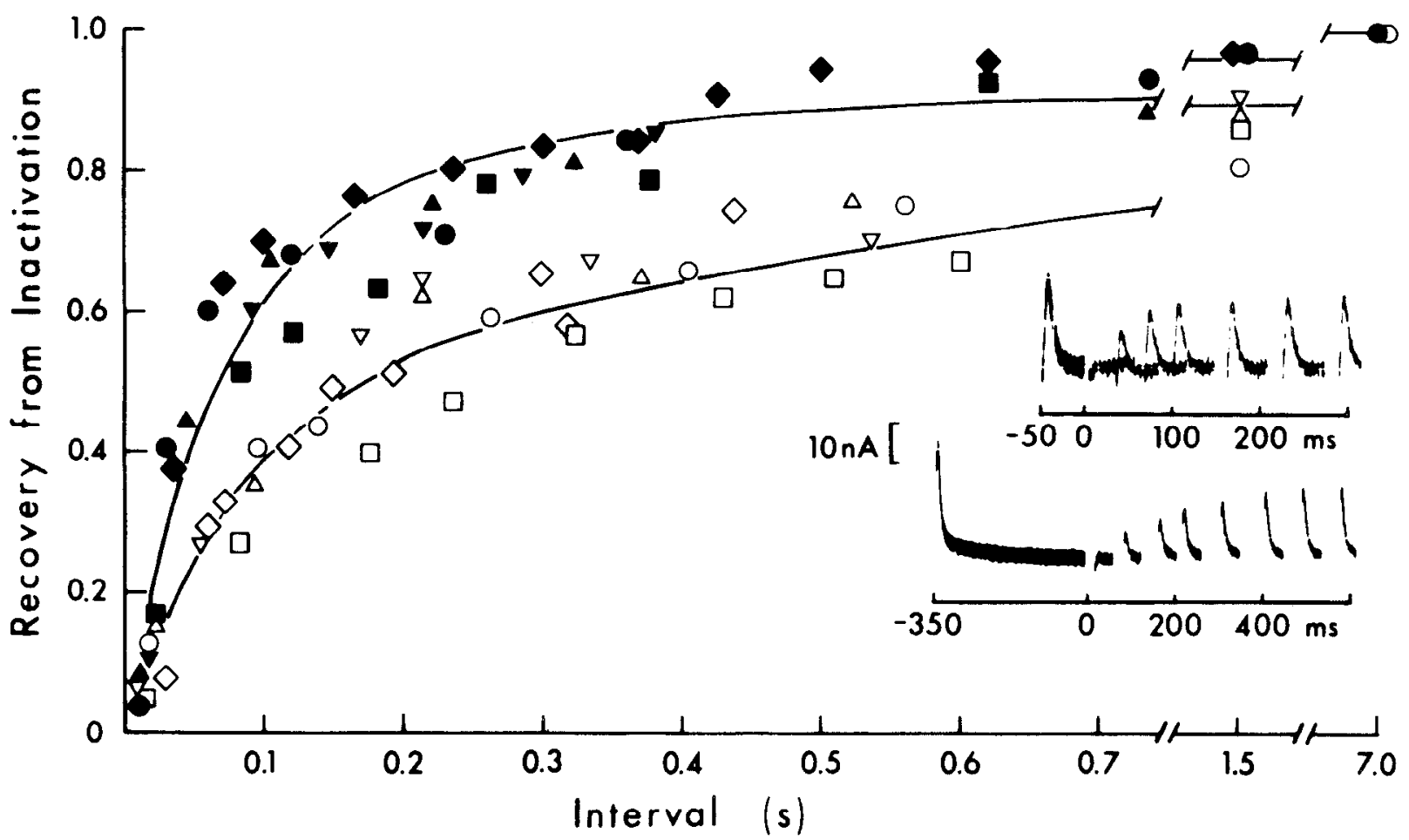

Figure 4. Time course of $I_{A}$ recovery from inactivation in normal fibers. Inactivation of $I_{A}$ was induced by a conditioning pulse depolarizing the membrane from $V_{H}=-50 \mathrm{mV}$ to $-10 \mathrm{mV}$ for the durations of $350 \mathrm{msec}$ (open symbo/s) and $50 \mathrm{msec}$ (solid symbo/s). To monitor the recovery of $I_{\mathrm{A}}$ upon repolarization, a test pulse to $-10 \mathrm{mV}$ was applied at variable time intervals following the end of the conditioning pulse. Examples of superimposed active current traces are shown in the inset. The graphs illustrate the fraction of $I_{A}$ recovery from inactivation as a function of duration of repolarization to $V_{H}$. Pooled data from different fibers at $15^{\circ} \mathrm{C}$ are represented by individual symbols. Continuous curves are derived from summation of two exponentials with time constants of 75 and $900 \mathrm{msec}$ of different proportions. See equation 3 in the text.

mutations. A more detailed analysis of these two alleles will be presented later (see "Altered I A properties in Sh alleles").

The traces in Figure 5 represent total membrane currents recorded from $S h^{M}$, $S h^{102}$, and $S h^{K S 133}$ and normal fibers elicited by step depolarizations from a $V_{H}$ of $-50 \mathrm{mV}$. Variation in the amplitude of total membrane currents at the plateau of $I_{K}$ reflects differences in fibers sizes (cf. Figs. 5 and 11). After adjustments for leakage currents and fiber surface area (see "Materials and Methods"), the density of the remaining active currents measured from a number of cells of the various $S h$ alleles is plotted as a function of voltage (Fig. 6). In the aforementioned three alleles, IA was entirely missing whereas the steady-state amplitude of the delayed outward current $I_{K}$ was not significantly different from nommal (Fig. 6A).

We have studied the remaining $/ K$ in greater detail for two reasons. First, normality of other properties of the $I_{K}$ in various Sh mutants provides a stringent proof for the hypothesis that $I_{\mathrm{A}}$ and $I_{\mathrm{K}}$ channels are genetically distinct and separable in larval muscles. Second, if the remaining $I_{K}$ is normal, then the $S h$ larval muscle fibers will be a favorable preparation for quantitatively describing normal $I_{\mathrm{K}}$ in isolation from $/ I_{A}$. Such a description provides a basis for comparison with other mutations reported to result in defective $l_{k}$ (Wu et al, 1983a; Wu and Ganetzky, 1984). The above considerations prompted us to examine $I_{K}$ further in the $S h$ larval muscle, comparing their kinetic and steady-state properties with those obtained in normal fibers.

Instantaneous $\mathrm{I}-\mathrm{V}$ relation and reversal potential of $I_{k}$. It is important to test whether the reversal potential for $I_{\mathrm{K}}$ is consistent with the hypothesis that $\mathrm{K}^{+}$is the major charge carrier through the channels. It is also of interest to examine whether voltage-dependent conductance change mediating the current has a linear instantaneous $\mathrm{IV}$ relationship (Hodgkin and Huxley, 1952a).

Figure $7 A$ shows the current tails obtained from a normal and a Sh fiber upon repolarizations to various potentials following a 200 msec conditioning depolarization to $+10 \mathrm{mV}$ in saline containing 2
$\mathrm{mM} \mathrm{KCl}$. The current tails decayed more rapidly with stronger repolarizations and became inward at certain levels of hyperpolarizations. The reversal potential and the instantaneous I-V relationships can be estimated from a family of $I_{\mathrm{K}}$ tail currents. The speed of our voltage clamp system allowed measurements of tail currents $4 \mathrm{msec}$ after the initiation of the repolarizing pulse. Estimation of an instantaneous I-V relation relied on extrapolation of the tail current. This procedure probably introduced little error because the time constant of the tail currents was generally much greater than $4 \mathrm{msec}$ (cf. Fig. 9) and the extrapolated values at $0 \mathrm{msec}$ were not substantially different from those at $4 \mathrm{msec}$. The instantaneous $\mathrm{I}-\mathrm{V}$ relations for a normal fiber and a $S^{102}$ fiber in saline containing $2 \mathrm{mM} \mathrm{KCl}$ are compared in Figure $7 B$ (solid symbols). Results from these cells and from 32 normal and 30 Sh cells indicate that $I_{k}$ channels exhibit rectification. For hyperpolarizations, inward current was much less than would have been predicted from a linear relationship.

The reversal potential $V_{k}$ was determined in two ways, as the repolarization voltage al which the $I_{K}$ tail current reversed direction, and as the voltage at which the $\mathrm{I}-\mathrm{V}$ relation and the instantaneous $\mathrm{I}-\mathrm{V}$ relation intersected. We found that the two methods gave the same value for $V_{k}$. For all normal cells examined, $V_{K}=-58.6 \pm 9.0$ $\mathrm{mV}$ (mean $\pm \mathrm{SD}, n=33$ ) in the $\mathrm{Ca}^{2+}$-free saline containing $2 \mathrm{mM}$ $\mathrm{KCl}$. Among all $S h$ alleles, including $S h^{K S 133}, S h^{M}$, and $S h^{102}$ in which $I_{A}$ was completely absent, the reversal potential $V_{K}=-56.8 \pm 11.5$ $\mathrm{mV}$ (mean $\pm \mathrm{SD}, n=31$ fibers) closely resembled that determined in normal fibers. Thus the $\left[\mathrm{K}^{+}\right]$gradient for $S h$ fibers appears to be normal.

The above reversal potential measurements lend support to the idea that $\mathrm{K}^{+}$is the principle charge carrier for $\mathrm{K}_{\mathrm{k}}$. This notion is further confirmed by the observation of shifts in the reversal potential caused by changes in external $\left[\mathrm{K}^{+}\right]$. As shown in Figure $7 B$ (open symbols), an increase in $\left[\mathrm{K}^{+}\right]$from 2 to $30 \mathrm{~mm}$ by substitution of external $\mathrm{K}^{+}$ for $\mathrm{Na}^{+}$shifted the $V_{K}$ to a more positive value (in 10 fibers, -30.0 $\pm 3.2 \mathrm{mV}$, mean $\pm \mathrm{SD}$ ). However, the magnitude of the shift is 

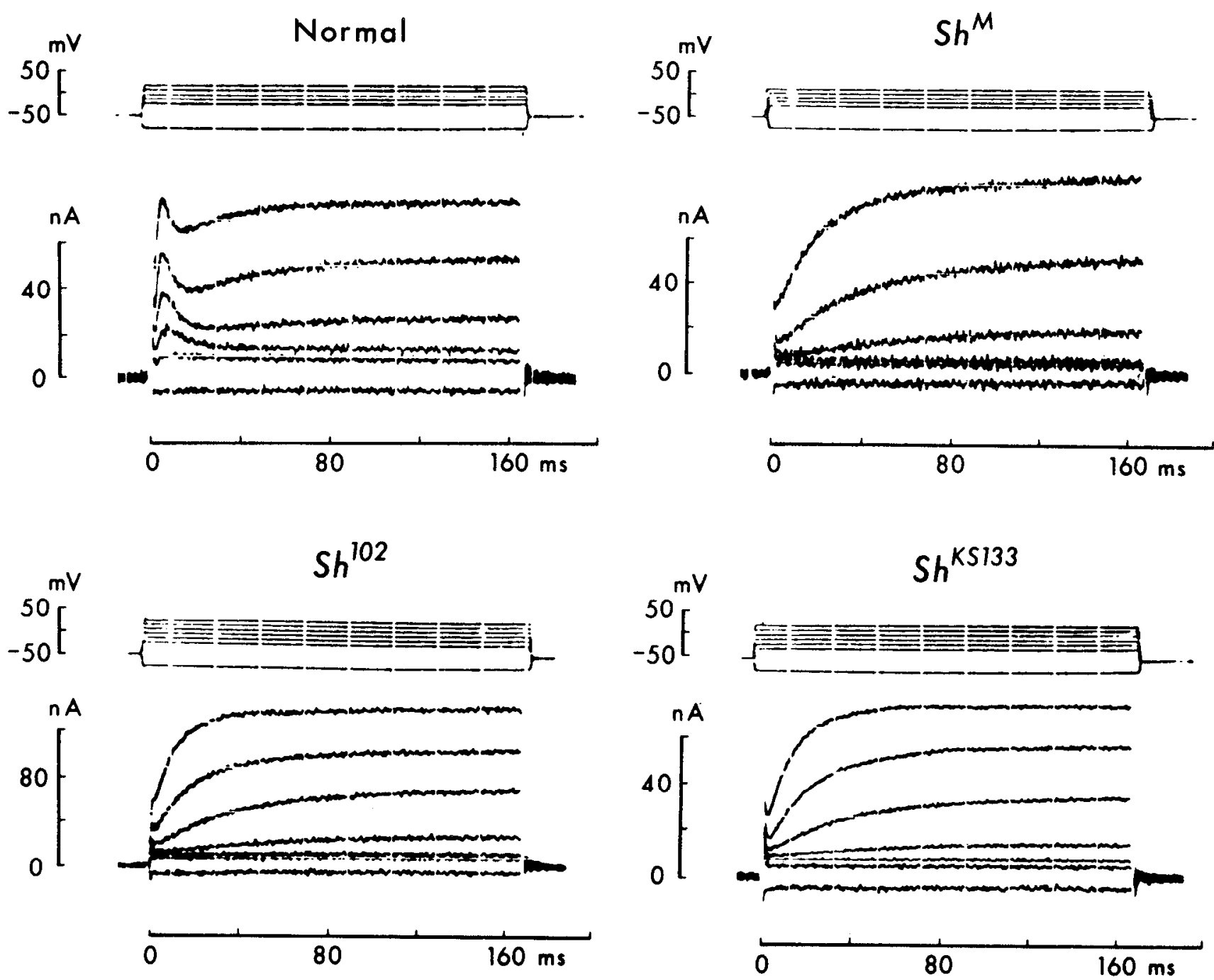

Figure 5. Total membrane currents recorded from normal, $S h^{K S 133}, S h^{M}$, and $S h^{102}$ muscle fibers. $V_{H}=-50 \mathrm{mV}, 15^{\circ} \mathrm{C}$. Note that, in these $S h a k e r$ mutants, the transient $I_{A}$ is not observed.

smaller than that which would be predicted by the Nernst equation for a perfect $\mathrm{K}^{+}$electrode (a predicted shift of $66 \mathrm{mV}$ in contrast to the observed value of about $28 \mathrm{mV}$ at $10^{\circ} \mathrm{C}$ ). This suggests that, as in other preparations (Hille, 1973; Yamamoto et al., 1981), $/ \mathrm{k}$ channels in Drosophila larval muscles are also slightly permeable to other ionic species.

The instantaneous I-V relation determined in saline containing higher $\left[\mathrm{K}^{+}\right]$(30 mM) remains nonlinear (Fig. 7B, open symbols). Therefore, the observed rectification property of $I_{K}$ channels cannot be fully accounted for by a steep concentration gradient for the charge carrier, $\mathrm{K}^{+}$.

Voltage dependency of conductance associated with $I_{k}$. Once $V_{K}$ is determined, the "steady-state" conductance $\left(g_{K}\right)$ associated with $I_{K}$ at various voltages can be defined according to the equation

$$
I_{K_{\max }}=g_{K}\left(V-V_{K}\right)
$$

where $I_{K_{\max }}$ is the maximum or "steady-state" current density driven by the potential gradient $\left(V-V_{K}\right)$ at the membrane potential, $V$.

Strictly speaking, this is an operational definition for $g_{k}$, which represents the conversion factor between $I_{K_{\max }}$ and $\left(V-V_{K}\right)$ measurements. Converting these measurements into permeability (Dodge and Frankenhaeuser, 1959) was not pursued because, without additional assumptions, the present definition of $g_{k}$ provides a convenient means for comparison among fibers from different mu- tants. Furthermore, this definition of $g_{\mathrm{K}}$ is also appropriate for our purpose because the instantaneous $\mathrm{H}-\mathrm{V}$ relation for $I_{K}$ is essentially linear over the voltage region of interest $(-30$ to $+30 \mathrm{mV}$; cf. Fig. 7B).

Results from a number of normal fibers examined at different $V_{H}$ and temperatures were first analyzed. Calculated values of $g_{k}$ were normalized and plotted as a function of the membrane potential $V$ in the semilogarithmic graph shown in Figure $8 A$. The continuous linc in the figure represents the initial slope of $e$-fold increase in $g_{k}$ per $6 \mathrm{mV}$, similar to the value found in squid axons (Hodgkin and Huxley, 1952a). It is evident that, within the range tested, the conductance approaches a maximum value for strong depolarizations ( $\geq 30 \mathrm{mV}$ ), and that the initial slope is not markedly altered by changes in temperature $\left(6\right.$ to $\left.21^{\circ} \mathrm{C}\right)$ or in holding potential $(-30$ to $-50 \mathrm{mV}$ ) (Fig. 8A).

We subsequently analyzed the voltage dependency of $g_{\mathrm{K}}$ for each of the alleles of $S h$. In Figure $8 B$, representative data from various alleles are normalized and compared. As in normal fibers, $g_{\mathrm{K}}$ increases with the strength of depolarization and approaches a maximum value for depolarizations exceeding $+30 \mathrm{mV}$. For direct comparisons between alleles, most fibers were examined at a temperature of 13 to $15^{\circ} \mathrm{C}$. No significant difference among fibers of all five mutants and the normal muscle could be detected. The line shown in Figure $8 B$ represents an initial slope (e-fold increase in $g_{k}$ per 6 $\mathrm{mV}$ ) identical to that drawn to fit the data for normal (Fig. $8 A$ ). 

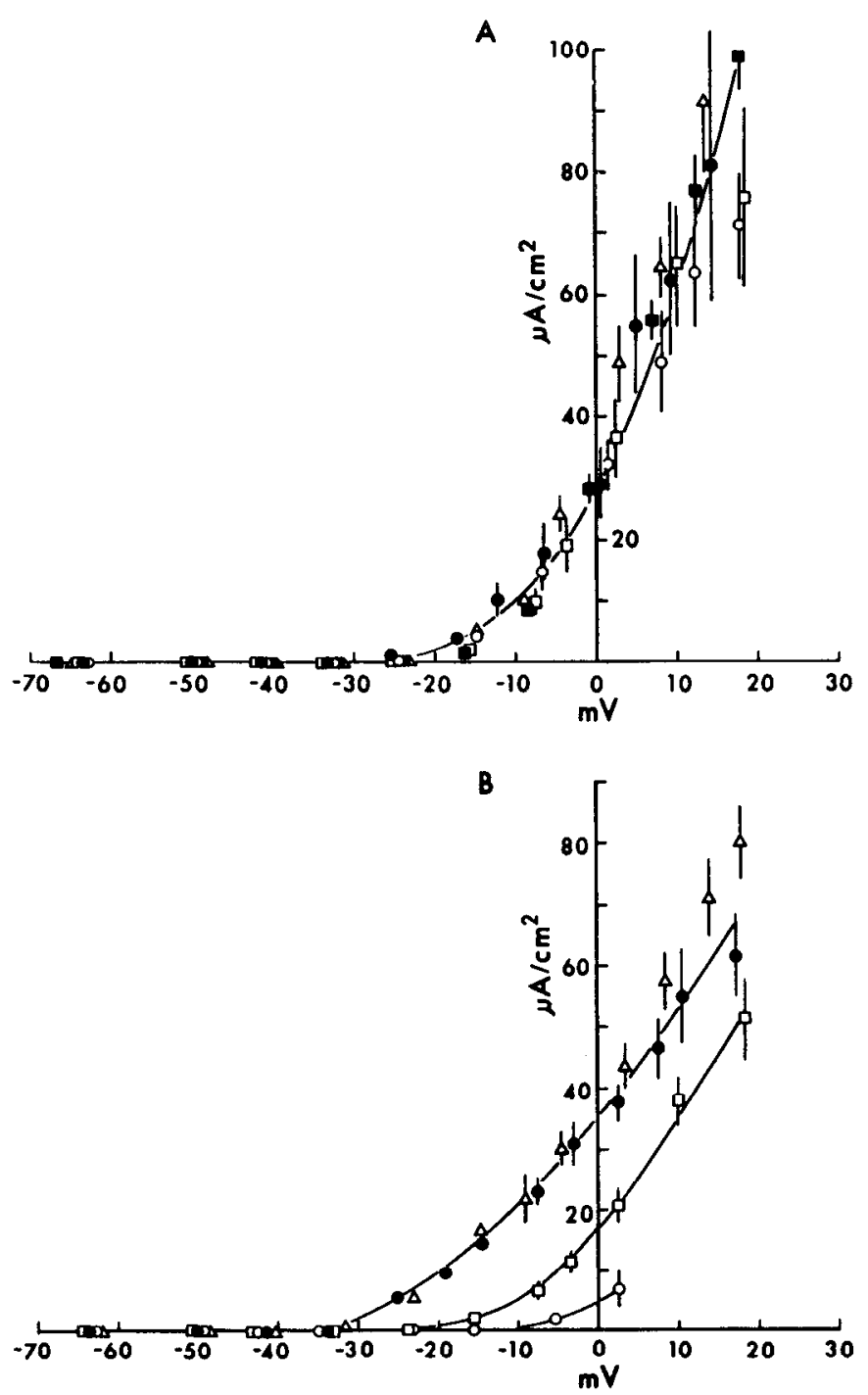

Figure 6. Pooled I-V relations for normal $\left(\boldsymbol{O}, 26\right.$ fibers), $S h^{\kappa S 133}(\mathrm{O}, 12$ fibers), $S h^{M}$ ( $\square, 5$ fibers), $S h^{5}$ ( $\square, 9$ fibers), and $S h^{r k 0120}$ ( $\triangle, 18$ fibers) at $V_{H}$ $=-50 \mathrm{mV}, 14$ to $15^{\circ} \mathrm{C}$. Each data point represents the current density (mean \pm SEM) after adjustment for leakage current and surface area. A, Active outward currents measured at the steady-state of $l_{\mathrm{k}}$. B. Active outward currents measured at the time of peak of $I_{A} . I_{A}$ is absent in $S h^{K S 133}, S h^{M}$, and $S h^{102}$ fibers, and only small active currents are present at more depolarized levels due to the rapid rise of $I_{K}$ (only $S h^{\kappa S 133}$ is represented in this I-V plot). In $S h^{r K 0120}$ cells, the current density of $I_{A}$ is not decreased. In $S h^{5}, I_{A}$ is reduced and is activated only at more depolarized lovels.

To illustrate the effect of temperature, data from one fiber $\left(S h^{K S 133}\right)$, at $6^{\circ} \mathrm{C}$, have been included as open circles in Figure $8 B$. The voltage dependency was not markedly altered or shifted by the reduced temperature. Neither was it affected by changing the holding potential to $V_{H}=-30 \mathrm{mV}$ (Fig. $8 B$, solid squares). Although the absolute value of $g_{K}$ was reduced at this holding potential due to inactivation (cf. Fig. 10), following normalization, the general form of the voltage dependency was not obviously altered in a number of normal and mutant cells examined.

Kinetics of $I_{k}$ tail currents. The above results indicate that the steady-state properties of $I_{\mathrm{k}}$ activation in $S h$ are normal. The rclaxa tion process of $l_{\mathrm{K}}$ activation was studied by analyzing the tail current kinetics of $I_{\mathrm{K}}$ in both $S h$ and normal fibers. Under the assumption that $I_{K}$ is mediated by a homogeneous species of channels, any substantial change in the time course of the tail current decay reflects an alteration in the rates of conversion between open and closed states of $I_{K}$ channels.
The same families of tail currents obtained with the experimental paradigm used to estimate $V_{K}($ e.g., Fig. 7A) were analyzed. Repolarizing steps to a voltage above $V_{k}$ from a depolarization of about $+10 \mathrm{mV}$ produced current tails which were outward and declined over tens of milliseconds. Upon hyperpolarization to a level more negative than $V_{k}$, the tail current turned inward but became smaller, due to the apparent rectification, and its decay followed a more rapid time course.

The time course of current tails in semilogarithmic plots were nonlinear, composed of a rapid initial decay and a slower second phase. However, the slow phase constituted the major part $(>70 \%)$ of the total tail current and could be approximated by exponential decay with a single time constant.

The time constant $\left(\tau_{s}\right)$ chosen to fit the slow phase is plotted as a function of voltage. Pooled data of $\tau_{s}$ from a number of normal and $S h$ cells at three different temperatures are summarized in Figure 9 . The $\tau_{s}$ shows a strong voltage dependence, decreasing at more negative membrane potentials. Figure 9 also illustrates that $\tau_{s}$ increased as the temperature was decreased. For example, at $-15 \mathrm{mV}, \tau_{s}$ was about $45 \mathrm{msec}$ at $15^{\circ} \mathrm{C}$ and about $120 \mathrm{msec}$ at $6^{\circ} \mathrm{C}$. This represents a $Q_{10}$ of about 3 over this temperature range.

Because of its more rapid kinetics and smaller amplitude, the time course of the initial fast decay could be reliably resolved only at low temperatures. Analysis of this component at $6^{\circ} \mathrm{C}$ revealed a process about 4 times faster than the slower major component in the tail current.

The families of data obtained from normal and Sh fibers are comparable in all aspects. The above results and the measurements of instantaneous $\mathrm{I-V}$ relations (Fig. 7) also imply that the tail currents in normal fibers reported here represent the true relaxation process of $I_{\mathrm{K}}$. At the plateau of $I_{\mathrm{K}}, I_{\mathrm{A}}$ is inactivated and does not produce a detectable tail current upon abrupt membrane repolarization.

Inactivation of $I_{k}$. As described above, $I_{K}$, unlike $I_{A}$, did not appear to inactivate during short depolarizing pulses. However, for prolonged depolarizations above $-10 \mathrm{mV}$, a slow decay of $I_{k}$ over many seconds could be observed. Brief hyperpolarizing pulses of less than a second completely reversed the effect of prolonged depolarization.

Inactivation of $I_{K}$ also occurs at potentials between -10 and -50 $\mathrm{mV}$, where $I_{\mathrm{K}}$ activation is minimal. Inactivation over this range may be demonstrated indirectly by an increase in current induced by a test pulse following a hyperpolarizing conditioning pulse (Fig. 10A). For various holding potentials, a brief $(200 \mathrm{msec})$ test pulse was first applied to measure the attainable $I_{\mathrm{K}}$. Interposed between this and a second identical test pulse was a period of hyperpolarization with an amplitude and duration sufficient to remove inactivation completely. After adjustment for leakage currents, the increment in $I_{K}$ evoked by the second test pulse was assumed to be $l_{K}$ recovering from inactivation. The ratio, $h_{k}$, between the $I_{k}$ evoked by the first and the second test pulse represents the fraction of $I_{K}$ which was not inactivated at the particular holding potential, $V_{H}$.

In a large number of experiments, $h_{k}$ was determined as a function of holding potentials in both normal and Sh muscle fibers (Fig. 10B). The results show that the fraction of $I_{K}$ attainable, or $h_{K}$, varied with the holding potential, ranging from 1.0 at $-50 \mathrm{mV}$ (no inactivation) to 0.2 at $-10 \mathrm{mV}(80 \%$ inactivation). Figure $10 \mathrm{~B}$ suggests that the steady-state $I_{K}$ inactivation in both $S h$ and normal larval muscles shows a similar voltage dependency. The continuous curve is given by the equation

$$
h_{k}=1 /\left[1+\exp \left(\frac{V+20}{8}\right)\right]
$$

where $V$ is the potential in $m V$ at which the membrane is held. This equation is similar to the one used to fit $h_{\mathrm{A}}$ for $I_{\mathrm{A}}$ inactivation (equation $2)$, with the difference that $I_{A}$ inactivation occurs at more hyperpolarized levels ( -40 instead of $-20 \mathrm{mV}$ for $50 \%$ inactivation) and shows a steeper voltage dependence. 

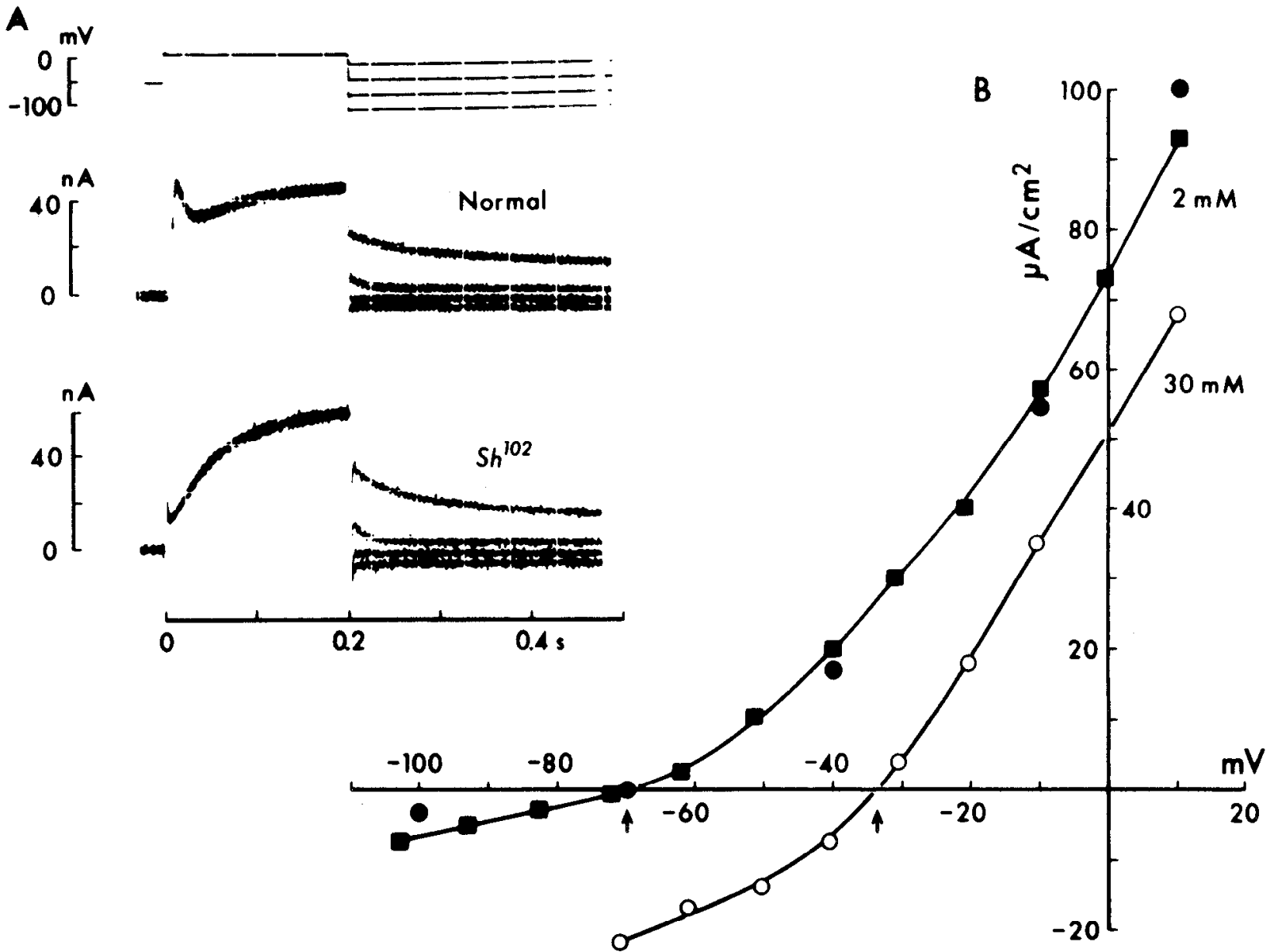

Figure 7. Reversal potential and instantaneous $\mathrm{I}-\mathrm{V}$ relations of $\mathrm{K}_{\mathrm{K}}$ in normal and $S h$ fibers. $A$, Examples of current tails associated with abrupt repolarization to different potentials after $200 \mathrm{msec}$ depolarization to $+10 \mathrm{mV}$ in standard saline $\left(2 \mathrm{mM} \mathrm{K}{ }^{+}\right) . V_{H}=-50 \mathrm{mV}, 10^{\circ} \mathrm{C}$. The superimposed voltage records of the normal fiber are shown to indicate the pulse paradigm. $B$, Instantaneous I-V relations in standard saline and in high $\mathrm{K}^{+}$saline ( $\left.30 \mathrm{~mm}\right)$. Data from normal (O). $S h^{102}(\mathbb{D})$, and $S h^{K S 133}(\mathrm{O})$ fibers are plotted after substraction of the leakage currents. Note that the nonlinearity in the instantaneous $\mathrm{I} V \mathrm{~V}$ relation is apparent at both $\left[\mathrm{K}^{+}\right]$. The reversal potential $\left(V_{K}\right)$ for each case is indicated by an arrow.

The data of Figure $10 B$ also indicate that the voltage dependence of the steady-state $l_{k}$ inactivation did not vary significantly within the temperature range used $\left(9\right.$ to $\left.21^{\circ} \mathrm{C}\right)$. Although the kinetics of inactivation slowed down at lower temperatures, similar steady-state levels of inactivation were reached.

The time course of inactivation of $l_{\mathrm{K}}$ at various $V_{H}$ was determined. Upon returning to a $V_{H}$ in question after a duration of hyperpolarization to remove all $I_{k}$ inactivation, a train of brief test pulses was applied. The currents elicited by the successive test puises declined to a steady-state value. The time course of inactivation followed a simple first-order kinetics. Normal and Sh muscle fibers were analyzed in this fashion and both yielded sirrilar results. Inactivation of $I_{\mathrm{K}}$ above $-10 \mathrm{mV}$ was directly monitored by the decay of $I_{\mathrm{K}}$ during prolonged depolarization. The inactivation of $/_{k}$ is voltage dependent. exhibiting faster kinetics at more depolarized levels. The time constant of inactivation at $15^{\circ} \mathrm{C}$ decreased from roughly 30 to $5 \mathrm{sec}$ when the membrane depolarization increased from -40 to $+10 \mathrm{mV}$.

The kinetics of recovery from inactivation were measured by two identical test pulses separated by a variable duration of hyperpolarization (cf. Fig. 10A). $I_{k}$ recovered more rapidly with stronger hyperpolarizations. The recovery process can be approximated by firstorder kinetics with time constants of 100,325 , and $700 \mathrm{msec}$ at hyperpolarizing potentials of $-95 \mathrm{mV},-62 \mathrm{mV}$, and $-55 \mathrm{mV}$, respectively.

\section{Altered $I_{A}$ properties in Sh alleles}

Analysis of $S h^{r k 0120}$. As mentioned above, $I_{\mathrm{A}}$ in larval muscles is completely abolished in three different alleles, $S h^{\kappa S 133}, S h^{M}$, and $S h^{102}$, but not in two other alleles, $S h^{5}$ and $S h^{\text {iko120. }}$. It is of interest to examine the residual $I_{A}$ in $S h^{5}$ and $S h^{r k 0120}$ for possible alteration in the function of $I_{\mathrm{A}}$ channels.

At the larval neuromuscular junction, $S h^{5}$ exhibits less enhanced synaptic transmission than do $S h^{K S 133}$ (Jan et al., 1977). $S h^{M}$, and $S h^{102}$ (C. - F. Wu and B. Ganetzky, unpublished observation). Neuromuscular transmission in $S h^{r k 0120}$ larvae is, in contrast, elevated to a degree similar to that found in $S h^{\kappa S 133}$ (Ganetzky and $W u, 1983$ ). Recombination of either of these two alleles with alleles of eag, a second gene found to affect potassium currents (Wu et al., 1983a), results in the same extreme phenotype of prolonged transmitter release lasting for hundreds of milliseconds (see "Materials and Methods" and Ganetzky and Wu, 1983, for a review of Sh'K0120 stocks). Therefore, it is reasonable to expect $S h^{r k 0120}$ larvae to have a defect in $I_{A}$ more severe than in $S h^{5}$ larvae (see below) and nearly as extreme as that in $S h^{\kappa S 133}$ larvae. However, we consistently observed that $I_{\mathrm{A}}$ in $S h^{r K 0120}$ was large and qualitatively similar to that in normal larval muscles.

The outward currents recorded from a $S h^{\text {rk1020 }}$ fiber are shown in Figure $11 A$. Results from 18 fibers examined are summarized in 


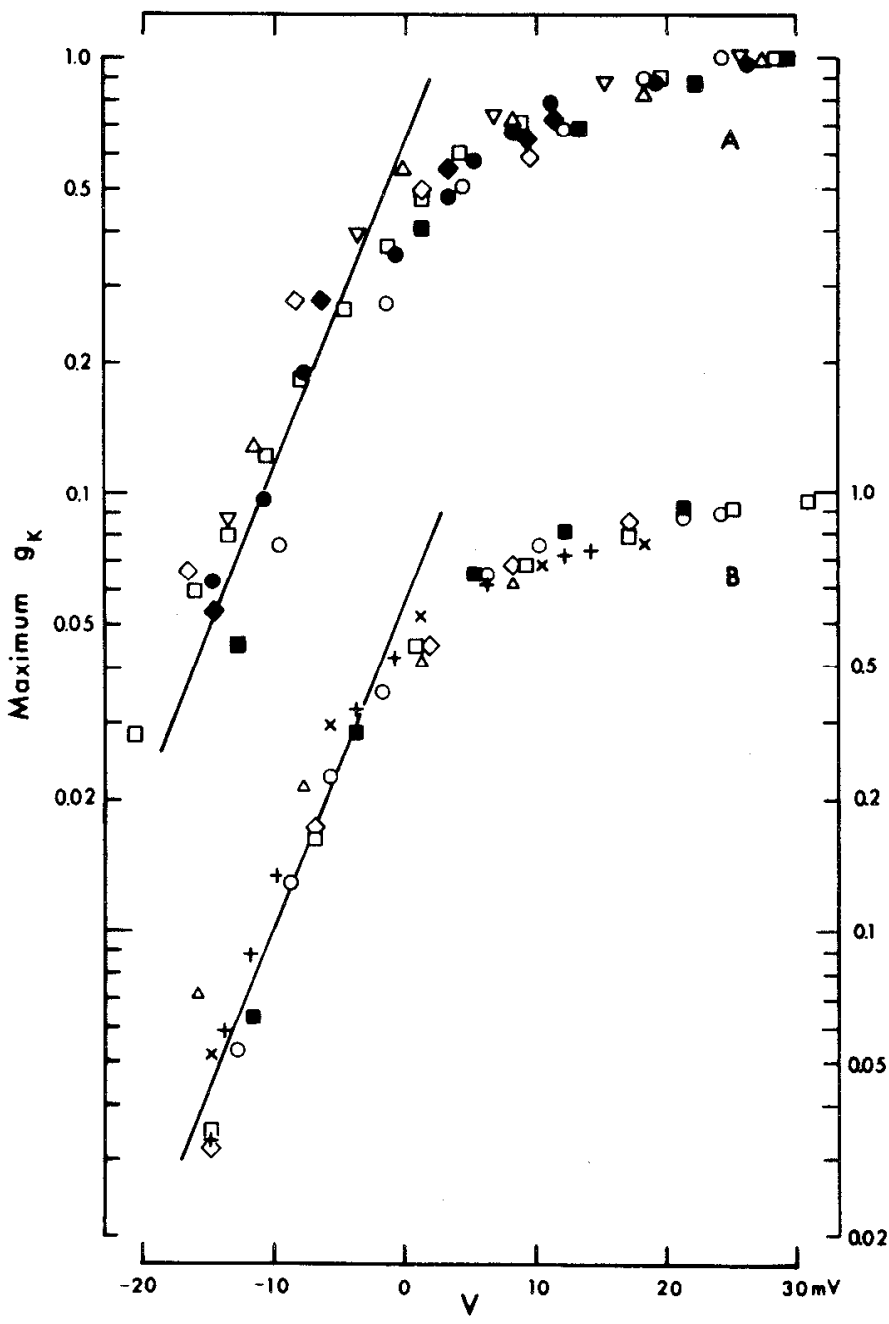

Figure 8. Voltage dependence of the conductance mediating $I_{k}$. After determination of $V_{k}$ for each cell, maximum conductances at different voltages are calculated according to equation 4 in the text and plotted in relative scale. $A$, Normal fibers. Data are from different fibers at $V_{H}=-50$ $\mathrm{mV}$ (open symbols) or $-30 \mathrm{mV}$ (solid symbols) at temperature ranges of 6 to $8^{\circ} \mathrm{C}$ (circles), $15^{\circ} \mathrm{C}$ (squares and triangles), and $21^{\circ} \mathrm{C}$ (diamonds). The continuous line represents an e-fold increase in $g_{\mathrm{K}}$ per $6 \mathrm{mV}$. B, Sh fibers. Data are from $S h^{\kappa S 133}$ at $6^{\circ} \mathrm{C}$ (open circles), $S h^{M}$ at $15^{\circ} \mathrm{C}$ (squares and diamonds), $S h^{r K 0120}$ at $15^{\circ} \mathrm{C}$ (open triangles), and $S h^{5}$ at 13 to $15^{\circ} \mathrm{C}$ (crnsses). $V_{H}=-50 \mathrm{mV}$ for all fibers except one $S h^{M}$ fiber (solid squares) where $V_{H}=-30 \mathrm{mV}$. The continuous line (e-fold increase in $g_{\mathrm{K}}$ per $6 \mathrm{mV}$ ) is identical to that shown in $A$.

Figure 6 and are compared with data obtained from fibers of other $S h$ alleles and normal larvae. Activation of $I_{A}$ in $S h^{r k 0120}$ occurred at normal potential levels (more negative than $I_{K}$ ). The $I-V$ relations are not significantly different from normal at the plateau of $I_{\mathrm{K}}$ (Fig. $6 A$ ) and the peak of $I_{A}$ (Fig. $6 B$ ). Furthermore, no obvious change in the activation kinetics of $I_{A}$ was detected. The time to peak $I_{A}$ upon step depolarization to $-15 \mathrm{mV}$ was about $9 \mathrm{msec}$ at $15^{\circ} \mathrm{C}$, as compared to about $9 \mathrm{msec}$ in normal fibers. Thus, it is imporant to inspect more closely other possible differences in the properties of $I_{\mathrm{A}}$ in $S h^{r k 0120}$ larvae. Experiments similar to those described above for normal $I_{\mathrm{A}}$ were performed on $S h^{r k 0120}$ fibers.

The steady-state level of inactivation was determined by the amplitude of $I_{A}$ activated upon step depolarization to $+10 \mathrm{mV}$ from various holding potentials (Fig. 12A). In Figure 12B, the peak $I_{\mathrm{A}}$ normalized to the maximum attainable value in $S h^{r k 0120}$ fibers (Fig. $12 B$, open triangles) is plotted against the holding potential and compared to the normal data (Fig. 12B, solid circles). The continuous curve in Figure $12 B$ is drawn according to equation 2, which was previously used to fit the normal data (Fig. 2). A slight but statistically significant change in the level of inactivation is indicated (Fig. 12B).

The time course of $I_{A}$ decay from its peak value at different depolarization levels was analyzed by using semilogarithmic plots. As in normal fibers, the decay is composed of an initial major component, which can be fitted by first-order kinetics, and a slower but smaller component, which is attributable to the slight activation of $/ \mathrm{k}$. The time constants of the major component determined at various potentials in a number of fibers at $15^{\circ} \mathrm{C}$ are shown in Figure $3 B$. The values exhibit a voltage dependence resembling that found in normal fibers (cf. $15^{\circ} \mathrm{C}$ data of Fig. $3 A$ ).

Figure 13 shows the time course of recovery of $I_{A}$ (at $-50 \mathrm{mV}$ ) from inactivation induced by a $50-\mathrm{msec}$ depolarizing pulse to -10 $\mathrm{mV}$. The data can be satisfactorily described by the same kinetic function (continuous curve in Fig. 13) used to fit normal data (Fig. 4, equation 3).

Except for a slight change in the voltage dependence of $I_{A}$ inactivation (Fig. 12B), our present investigation failed to reveal any clear qualitative change in the properties of $I_{\mathrm{A}}$ in $S h^{r k 0120}$ muscle fibers despite the fact that the abnormal neuromuscular transmission in this mutant is as extreme as that found in $S h^{K S 133}$ (see "Discussion").

Analysis of $S h^{5}$. The $S h^{5}$ larvae exhibit only a mild increase in neuromuscular transmission. Ether-anesthetized $S h^{5}$ adults display a characteristic scissoring of the wings (Kaplan and Trout, 1969) in addition to the leg-shaking behavior associated with all $S h$ alleles. It has been reported that in developing adult flight muscles of $\mathrm{Sh}^{5}$, activation of $I_{\mathrm{A}}$ is normal but inactivation of $l_{\mathrm{A}}$ follows abnormally rapid kinetics (Salkoff, 1983b).

Surprisingly, contrasting results were obtained from $S h^{5}$ larval muscles demonstrating that $I_{A}$ is reduced in amplitude and altered in voltage sensitivity. Among cells from different larvae, or even within the same larva, the extent of decrease in $I_{A}$ was variable. Its appcarance varicd from barely detectable shoulders (Fig. 11B) to more defined peaks (Fig. 12A) riding on the rising phase of $I_{\mathrm{K}}$.

The diminished $I_{A}$ in $S h^{5}$ muscles is a result of a shift in the voltage dependence of activation to more positive levels but not a consequence of an altered reversal potential or excessive inactivation.

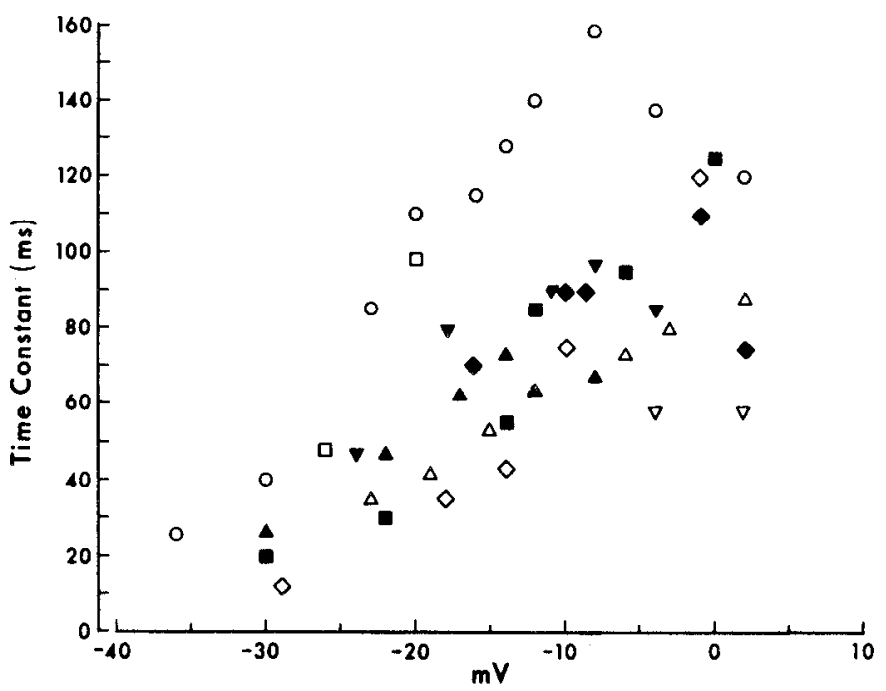

Figure 9. Voltage and temperature dependence of the time constant $\tau_{s}$ of the major component of $I_{K}$ tails. See the text for details. Time constants at $6^{\circ} \mathrm{C}\left(S h^{\kappa S 133}\right.$ : O; normal: $\square$ ), 9 to $11^{\circ} \mathrm{C}\left(S h^{5}: \Delta\right.$; normal: $\boldsymbol{\square}, \bullet$ ), and $15^{\circ} \mathrm{C}$ $\left(S h^{M}: \Delta\right.$; normal: $\left.\diamond\right)$ are plotted as a function of membrane potential. 
A

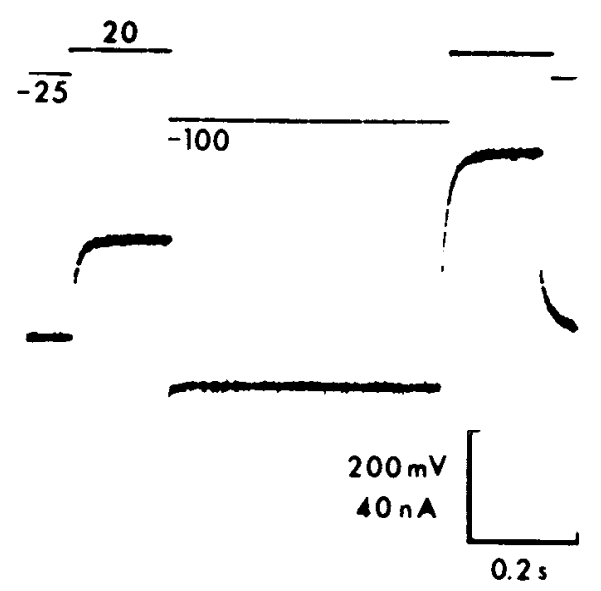

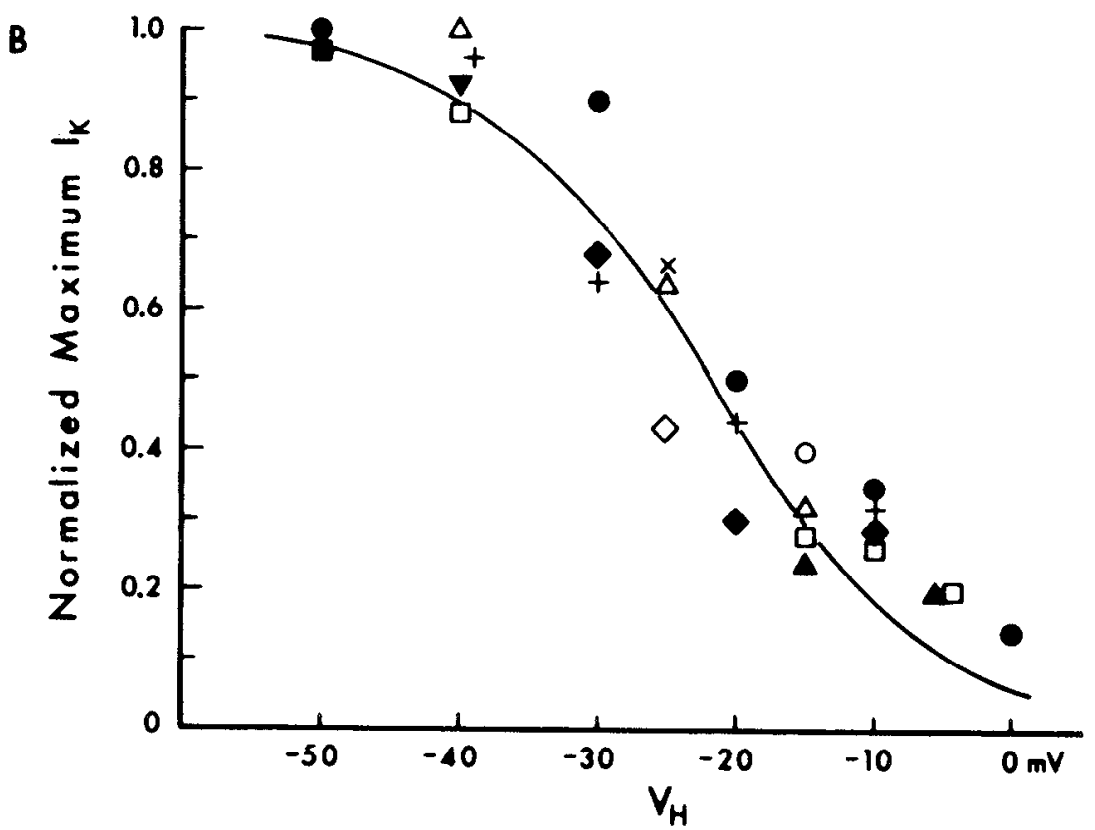

Figure 10. Voltage dependence of the steady-state inactivation of $I_{\mathrm{K}}$. A, Total membrane currents elicited from $V_{\mathrm{H}}=-25 \mathrm{mV}$ by test pulses to $20 \mathrm{mV}$ before and after a hyperpolarizing interval sufficient to remove inactivation. $S h^{r k 0120}, 15^{\circ} \mathrm{C} . B$, Pooled data from normal fibers at 9 to $11^{\circ} \mathrm{C}\left(\mathbf{\square}, \theta^{\circ}\right), 15^{\circ} \mathrm{C}(\mathbf{A})$, and $21^{\circ} \mathrm{C}(\diamond), S h^{M}$ at $15^{\circ} \mathrm{C}(\Pi, O) ; S h^{K S 133}$ at $15^{\circ} \mathrm{C}(\Delta) ; S h^{r k 0120}$ at $15^{\circ} \mathrm{C}(\diamond) ;$ and $S h^{5}$ at $10^{\circ} \mathrm{C}(+)$ and $15^{\circ} \mathrm{C}(x)$. Maximum amplitudes of $l_{\mathrm{K}}$ are normalized and plotted as a function of $V_{H}$. The continuous curve is calculated from equation 5 . See the text.
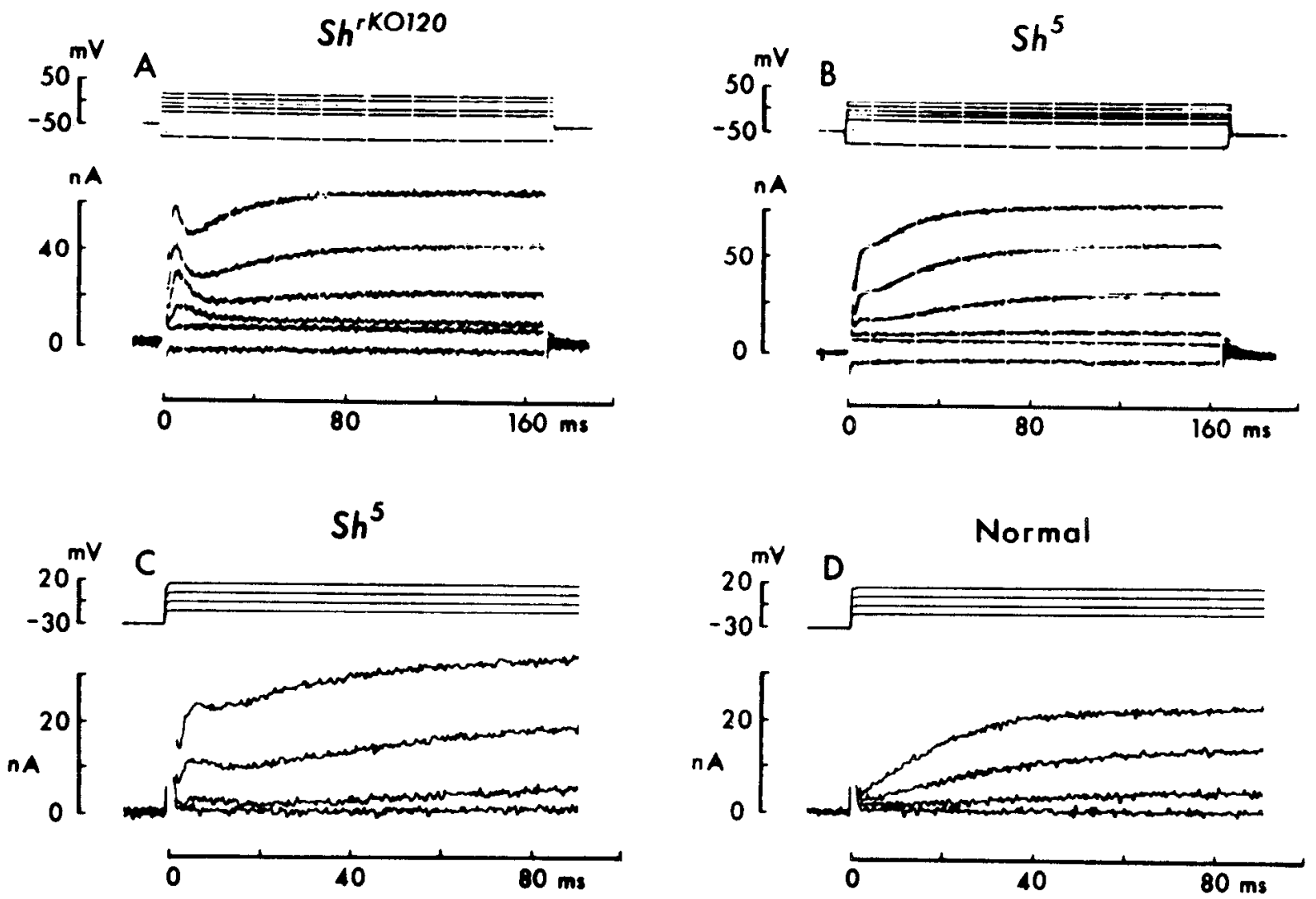

Figure 11. Total membrane currents recorded from $S h^{r k 0120}, S h^{5}$, and normal fibers at $15^{\circ} \mathrm{C} . A, S h^{r k 0120}, V_{H}=-50 \mathrm{mV}$. Note the presence of the transient $I_{A}$ and its amplitude relative to $I_{K}$ (cf. Figs. $5 A$ and 6 ). $B, S h^{5}, V_{H}=-50 \mathrm{mV}$. Note that $I_{A}$ is reduced in amplitude and activated only at the same depolarization levels as $I_{K}$ (cf. Fig. 6). $C, S h^{5}, V_{H}=-30 \mathrm{mV}$. Insufficient inactivation of $I_{\mathrm{A}}$ is evident in this fiber with larger residual $I_{\mathrm{A}}$ (see the text). $D, N o r m a l, V_{H}=-30$ $\mathrm{mV} . I_{A}$ is nearly completely inactivated at this $V_{H}$ (cf. Fig. 2). This fiber was smaller in size than the fiber used in $C$ and had less leakage and active currents. Total membrane currents are shown in $A$ and $B$; active currents (after adjustment for leakage) are presented in $C$ and $D$. 
A
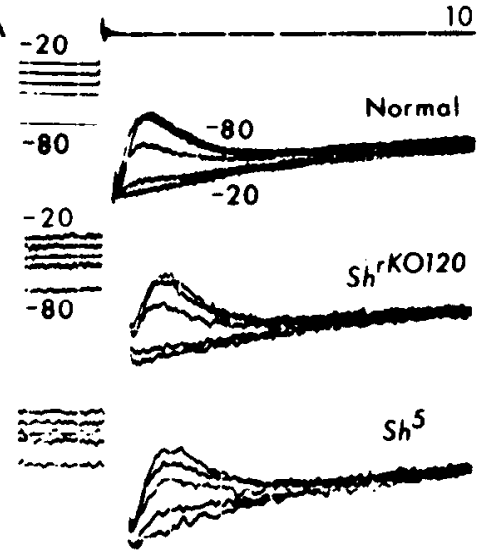

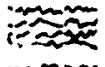

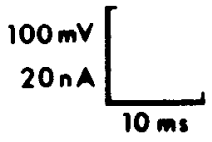

10

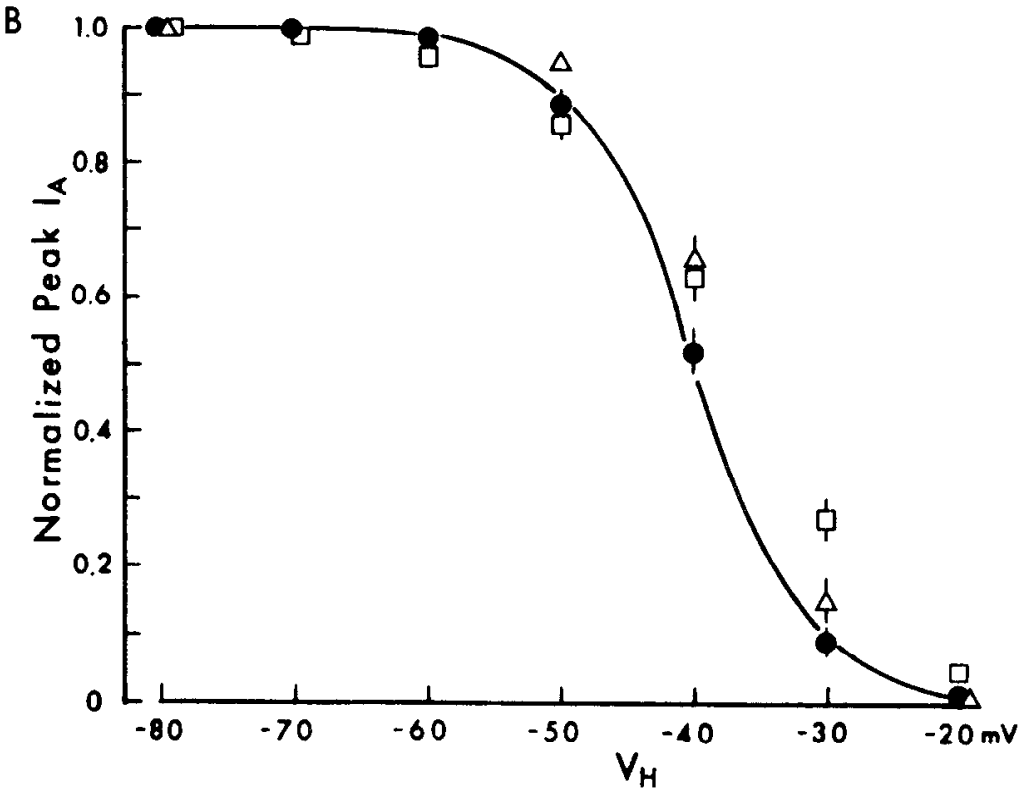

Figure 12. Voltage dependence of steady-state inactivation of $I_{\mathrm{A}}$ in $S h^{r k 0120}$ and $S h^{5}$ as compared to normal at $15^{\circ} \mathrm{C} . A_{1}$ Membrane currents elicited by voltage steps to $+10 \mathrm{mV}$ from the different holding potentials $\left(V_{H}\right)$ indicated. Note that the rise of $I_{k}$ delineates the base line. The superimposed voltage records of the normal fiber are shown to indicate the pulse paradigm. $B$. Pooled data from $11 S h^{r k 0120}(\Delta)$ and $11 S h^{5}(\square)$ fibers are compared to data from 14 normal fibers $(O)$. Peak amplitudes of $I_{A}$ are normalized and the mean and SEM are presented. The continuous curve (equation 2) fit to normal data is identical to that shown in Figure 2. All data were obtained by using the procedure shown in $A$.

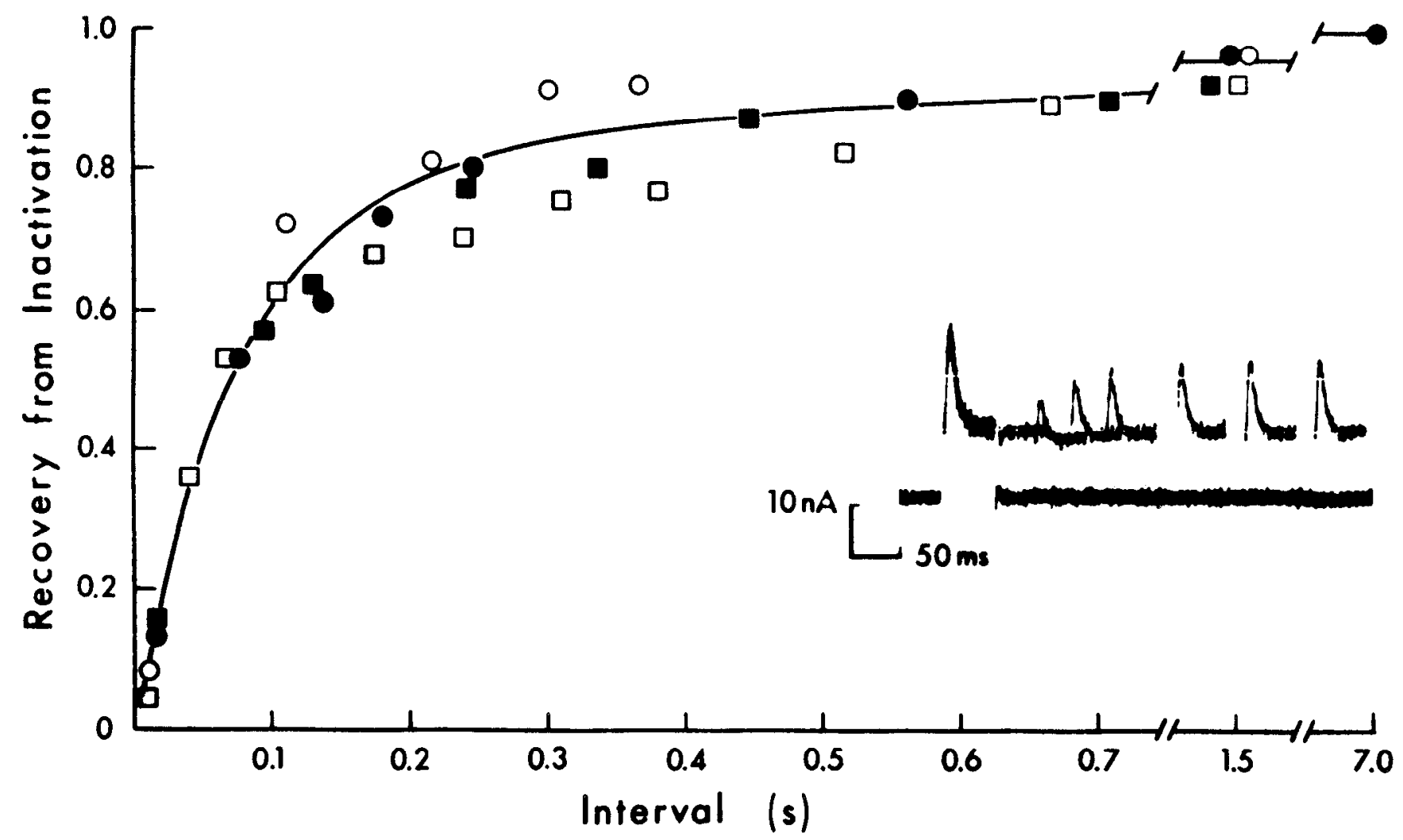

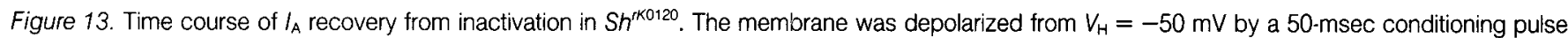
to $-10 \mathrm{mV}$ and then repularized to $V_{H}$. The recovery of $I_{\mathrm{A}}$ was tested by a second identical test pulse after various time intervals following the repolarization. An example of superimposed current traces is shown in the inset. Each symbol represents data from one of four fibers at $15^{\circ} \mathrm{C}$. The continuous curve is identical to the one used to fit normal data in Figure 4. 
Examination of the tail currents of $I_{A}$ in $S h^{5}$ did not reveal a substantial change in the reversal potential (about $-50 \mathrm{mV}$ in normal fibers) to account for the reduced amplitude of $I_{A}$. Changing the holding polential $\left(V_{H}=-50 \mathrm{mV}\right)$ to more negative voltages $\left(V_{H}=-60\right.$ and $-70 \mathrm{mV}$ ) did not significantly increase the amplitude of $I_{A}$. Nevertheless, in all $47 S h^{5}$ cells studied, $I_{\mathrm{A}}$ was no longer activated at more negative potentials but was only detectable at the same depolarizing potentials which activated $I_{\mathrm{K}}$ (Fig. $11, B$ and $C$ ).

Statistics from $S h^{5}$ cells at $V_{H}=-50 \mathrm{mV}$ are compared with those of normal and other $S h$ alleles in the $1-V$ relations shown in Figure 6. It can be seen that there is no significant difference in the $\mathrm{I}-\mathrm{V}$ relations at the plateau of $I_{K}$ (Fig. $6 A$ ), whereas the $\mathrm{I}-\mathrm{V}$ relations at the peak of $I_{A}$ is clearly abnormal in $S h^{5}$ (Fig. $6 B$ ). Alteration in the voltage dependence of $I_{A}$ activation in $S h^{5}$ becomes even more evident when the I-V relations at the peak of $I_{A}$ are corrected for the contributions from $I_{K}$ activation at this time (see data of $S h^{K S 133}$ in Fig. 6B).

In view of the change in the voltage dependence of $I_{A}$ activation, it is of importance to investigate $I_{A}$ inactivation in $S h^{5}$ cells for clues of a relationship between these two voltage-sensitive processes. The voltage dependence of $I_{A}$ inactivation is in fact also shifted to more positive levels, as indicated by the persistence of $I_{A}$ at more depolarized holding potentials. Insufficient inactivation of $I_{A}$ was cvident at $V_{H}=-30 \mathrm{mV}$ in $S h^{5}$ cells with larger residual $I_{A}$ (Fig. $11 C$ ), whereas $I_{A}$ in normal cells (Fig. 11D) was virtually completely inactivated at this $V_{\mathrm{H}}$.

The steady-stage inactivation of $I_{A}$ in $S h^{5}$ was determined by depolarizing pulses to $+10 \mathrm{mV}$ from various holding potentials $\left(V_{H}\right)$. The $I_{A}$ evoked in $S h^{5}$ was smaller than normal but readily quantifiable in cells with larger $I_{A}$ (Fig. 12A). Results from a number of $S h^{5}$ cells are summarized and compared to those of normal and $S h^{r k 0120}$ fibers in Figure $12 B$. Compared with normal fibers, the steady-state inactivation of $I_{A}$ in $S h^{5}$ cells shows a less steep voltage dependence with a shift (about $5 \mathrm{mV}$ ) to more positive potentials. The difference at more positive levels $(-20 \mathrm{mV})$ may be underrepresented because the small residual $I_{A}$ in $S h^{5}$ at these potentials was often masked by noise, leading to an overestimate of inactivation.

Measurements of kinetic properties of the remaining $I_{\mathrm{A}}$ in $S h^{5}$ larvae were difficult, because it is not possible to separate it from $I_{K}$ in any voltage range. However, estimations of the rise time (about 7 $\mathrm{msec}$ to peak $+10 \mathrm{mV}, 15^{\circ} \mathrm{C}$ ) and the half-time of decay (about 8 msec at $+10 \mathrm{mV}, 15^{\circ} \mathrm{C}$ ) of the residual $I_{A}$ were not substantially different from normal.

\section{Discussion}

Membrane currents in larval muscles. Analysis of Drosophila larval muscles has revealed several physiologically distinct membrane currents similar to those found in other insect muscles ( $Y$ amamoto and Washio, 1981; Yamamoto et al., 1981; Ashcroft and Stanfield, 1982). Voltage-dependent $\mathrm{Ca}^{2+}$ channels are responsible for the inward current but $\mathrm{Na}^{+}$channels are not detectable in the larval muscles, consistent with a previous current clamp study (Suzuki and Kano, 1977). The outward currents can be effectively isolated by using $\mathrm{Ca}^{2+}$-free saline which completely abolishes the inward current, revealing two different components of outward $\mathrm{K}^{+}$ currents, $I_{\mathrm{A}}$ and $I_{\mathrm{K}}$.

We have not systematically searched for a $\mathrm{Ca}^{2+}$-dependent $\mathrm{K}^{+}$ conductance (Meech, 1978) in the larval muscle. A fast transient of $\mathrm{Ca}^{2+}$-dependent outward current has been reported in the larval muscle of Tenebrio (Yamamoto and Washio, 1981) and in the adult flight muscles of Drosophila (Salkoff, 1983a). The present voltage clamp study can be extended, by using saline containing $\mathrm{Ca}^{2+}$, to determine whether a $\mathrm{Ca}^{2+}$-dependent $\mathrm{K}^{+}$conductance is also present in the larval muscles of Drosophila.

Properties of $I_{k}$. Comparison between the properties of $l_{K}$ in normal and $S h$ larval muscles does not reveal any essential difference (cf. Figs. 6 to 10). These results strongly suggest that $S h$ mutations do not affect $I_{K}$ and that, in normal larvae, at the time $I_{K}$ reaches a plateau value, $I_{A}$ is inactivated and does not contribute to the behavior of the outward current (e.g., tail currents).

The delayed outward current $l_{k}$ in Drosophila larval muscles resembles the delayed rectifier reported in other excitable tissues. The voltage dependency of activation of conductance $g_{k}$ has an initial slope of about $e$-fold $/ 6 \mathrm{mV}$ (e-fold increase per 6-mV depolarization) and reaches saturation at about $+30 \mathrm{mV}$ as compared to the corresponding values of e-fold $/ 6.5 \mathrm{mV}$ and $+30 \mathrm{mV}$ in the squid giant axon (Hodgkin and Huxley, 1952a) and about e-fold/10 mV and $+112 \mathrm{mV}$ in the larval mealworm muscle (Yamamoto and Washio, 1981).

In Drosophila larval muscles, $I_{K}$ inactivates slowly, resembling the observations reported in a number of different tissucs including frog skeletal muscles (Adrian et al., 1970) and adult stick insect muscles (Ashcroft and Stanfield, 1982). Depletion of intracellular $\mathrm{K}^{+}$or accumulation of external $\mathrm{K}^{+}$in the vicinity of the membrane surface may also lead to decline of $l_{k}$. However, these factors are not likely to interfere with our measurements of $I_{K}$ inactivation to a significant extent for the following reasons. First, $l_{K}$ inactivation reaches a level of $50 \%$ at $V_{H}=-20 \mathrm{mV}$, a potential at which $/_{\mathrm{K}}$ is not even activated (Figs. $6 A$ and 10). Second, in saline containing a high concentration $(30 \mathrm{~mm})$ of $\mathrm{K}^{+}$, the same steady-state level of inactivation is reached $\left(h_{\mathrm{A}}=0.5\right.$ at $\left.V_{\mathrm{H}}=-20 \mathrm{mV}\right)$, indicating that the measurements are independent of external $\mathrm{K}^{+}$concentrations (unpublished observations). Third, the actual depletion or accumulation of $\mathrm{K}^{+}$is probably not serious after all, because prolonged activation of $I_{K}$ (at $V_{H}=+10$ $\mathrm{mV}$ for seconds) does not shift the reversal potential $V_{k}$ (data not shown).

The instantaneous $\mathrm{I}-\mathrm{V}$ relation of $I_{\mathrm{K}}$ displays a pronounced outward rectification. This tail current behavior cannot be entirely attributed to the steep concentration gradient for the charge carrier because the apparent rectification persists in saline containing higher concentrations of $\mathrm{K}^{+}$(Fig. 7B). However, we cannot rule out the possibility of a very rapid ( $\ll 5 \mathrm{msec}$ ) decay of inward tail currents not resolvable by the present voltage clamp system.

The time course of $I_{K}$ tail currents deviates from that of first-order kinetics. This can be accounted for by a heterogeneous population of $I_{k}$ channels or a sequential scheme of the $I_{K}$ channel kinetics with a number of closed and open states (Conti and Neher, 1980). The Dossibility of distortion of channel kinetics by accumulation of $\mathrm{K}^{+}$in restricted extracellular space can be excluded as described above. In fact, tail currents obsenved in high $\mathrm{K}^{+}$saline $(30 \mathrm{~mm})$ displayed the same kinetics (data not shown).

Comparison with adult muscles. Our observations are in general agreement with the findings in the adult flight muscles of Drosophila (Salkoff and Wyman, 1983). However, there are certain important differences between these two sets of muscle fibers in the properties of $I_{A}$ and $I_{K}$. These two currents in the larval muscle can be physiologically separated. Because $I_{K}$ is activated at a more positive level, depolarization to the range between -35 and $-20 \mathrm{mV}$ from a holding potential, $V_{H}<-50 \mathrm{mV}$ evokes mainly $I_{\mathrm{A}}$. Conversely, at more positive holding potentials $\left(V_{H}>-30 \mathrm{mV}\right), I_{A}$ is inactivated and only $I_{\mathrm{K}}$ remains. In contrast, $I_{\mathrm{A}}$ and $I_{\mathrm{K}}$ in the adult flight muscle show similar $\mathrm{I}-\mathrm{V}$ relations and are both activated at about $-40 \mathrm{mV}$. Moreover, the behavior of tail currents indicates that the channels mediating $l_{K}$ are different in rcctification properties in these two sets of muscles. In larval muscles, the current is strongly rectified in the outward direction (Fig. 7), whereas large inward tail currents of $/ k$ can be elicited in the adult muscles (Salkoff and Wyman, 1983). However, a more quantitative comparison between $l_{k}$ in these two sets of muscles of different developmental stages is not yet possible because analyses of the instantaneous $I-V$ relation, the reversal potential, and the kinetics of tail currents of $I_{K}$ in adult muscles have not been reported. In addition to the above discrepancies, there appear to be intriguing differences in the effects of certain $S h$ mutations on the properties of $I_{A}$ in the larval and adult muscles, as discussed in detail below. 
Nature of $S h$ mutations and properties of $I_{A}$. Alterations in the functioning of ionic channels may be derived from changes in a number of molecular and cellular mechanisms, including primary protein structures, post-transcriptional or post-translational modifications, and assembly of subunits. At present, it is not possible to pinpoint the mechanism responsible for the altered $I_{A}$ in Sh mutants solely by electrophysiological means. Nevertheless, useful information concerning $I_{\mathrm{A}}$ channels can be gained by comparing the present findings with previous observations on various Sh alleles.

Evaluation of the effects of the same mutation on different excit able tissues at various developmental stages is of particular interest. In terms of severity, consistency is found in the defects of $S^{K S 133}$, $S h^{M}$, and $S h^{102}$, each causing delayed repolarization of action potentials in adult "giant axons" (Tanouye et al., 1981), prolonged transmission in larval neuromuscular junctions (Jan et al., 1977; Ganetzky and Wu, 1983; B. Ganetzky and C. -F. Wu, unpublished data), and complete elimination of $I_{A}$ in both pupal (Salkoff, 1983b; $S h^{M}$ not tested) and larval muscles. In contrast, $S h^{r k 0120}$ causes abnormal larval neuromuscular transmission to an extent indistinguishable from that in $S h^{\kappa S 133}$ but leads to only mild defects in the adult "giant axon" action potentials and no obvious change in properties of $I_{A}$ in larval muscles. (There has been a report (Salkoff and Wyman, 1981) on the complete elimination of $I_{\mathrm{A}}$ in adult $S h^{r K O 120}$ muscles. It was later found to be due to a different strain which has since been renamed $S h^{\text {KO120 }}$ (Salkoff, 1983a, b; L. Salkoff, personal communication).)

The defects caused by $S h^{5}$ have been found to be consistently less extreme than those in $S h^{\kappa S 133}$ in all tissues examined (larval neuromuscular junctions: Jan et al., 1977; C. -F. Wu and B. Ganetzky, unpublished observations; adult "giant axons": Tanouye et al., 1981; adult muscles: Salkoff and Wyman, 1981; larval muscles: this report). However, voltage clarmp studies of the residual $I_{A}$ in $S h^{5}$ revealed important differences in the manner in which adult and larval muscles are affected. The $I_{A}$ in adult flight muscles retains a normal peak amplitude but exhibits abnormally fast decay (Salkoff and Wyman, 1981) due to a change in the voltage dependence of inactivation kinetics (Salkoff, 1983b). In contrast, the $I_{A}$ in $S h^{5}$ larval muscles shows a reduced amplitude and a shift in the voltage dependency of both activation and inactivation, indicating that these two processes are not controlled by two independent, discrete parts of the channel. The fact that the same mutation alters both activation and inactivation in larvae but only inactivation in adults points up a differential expression of a common mechanism underlying these two processes in the two sets of muscles.

A comparative study of nerve and muscle membranes of different $S h$ alleles can reveal additional interrelationships among various functional components of potassium channels and provide a more complete view of the roles of the Sh gene product (or products) in different excitable membranes. More incisive analysis of mutant potassium channels can be achieved by patch recording from cultured Drosophila neurons (Wu et al., 1983b; Sun and Wu, 1984).

Molecular identities of potassium channels. By physiological and pharmacological criteria, a variety of potassium channels have been identified, which vary in distribution among different cellular regions and cell types displaying a spectrum of signaling capability (Adams et al., 1980; Kandel and Schwartz, 1982; Serrano, 1982; Alkon, 1983). It should be possible to modify and separate various potassium currents by genetic means. This approach will ultimately lead to the molecular identities of potassium channels by isolating the gene products of interest with recombinant DNA techniques (Jan et al., 1983; Ganetzky and Wu, 1984; Kamb et al., 1984). Evidence supporting the hypothesis that the Sh locus contains the structural gene for a potassium channel has been reviewed by Jan et al. (1983). However, caution must be exercised in implicating a simple one-to-one correspondence between a specific gene product and a particular potassium channel. The physiological properties and pharmacological sensitivities of $I_{\mathrm{A}}$ and $I_{\mathrm{K}}$ often show a varying degree of overlap in different excitable tissues, and sometimes an absolute distinction is difficult (Adams et al., 1980; Serrano, 1982). Furthermore, differences between the properties of $I_{A}$ in the adult and larval muscles and the differential effects of $S h^{r K O 120}$ and $S h^{5}$ on various types of excitable membranes suggest that the genetic control of $I_{A}$ channels involves other genes in addition to Sh. In fact, mutations of a second gene, eag, have been reported to alter potassium currents in both larval nerve and muscle membranes (Ganetzky and Wu, 1983; Wu et al., 1983a, Wu and Ganetzky, 1984).

Taking the above findings together, the hypothesis can be put forward that particular types of potassium channels are composed of specific functional components (e.g., subunits) and may share some components with other types of potassium channels. In consequence, a single-gene mutation can affect different potassium channels and a particular channel type can be affected by mutations of different genes. Thus, combination of a relatively small number of interacting gene products can yield a rich variety of potassium channels subserving an array of physiological activities in different excitable membranes. It should be possible to verify this notion by analysis of double-mutant combinations of the relevant genes. The interrelationships among subunits will be indicated by altered functional parameters of channels which may serve as a guide for molecular genetic analysis of potassium channels.

\section{References}

Adams, D. J., J. S. Stephen, and S. H. Thompson (1980) lonic currents in mulluscan soma. Annu. Rev. Neurosci. 3: 141-167.

Adrian, R. H., W. K. Chandler, and A. L. Hodgkin (1970) Voltage clamp cxpcriments in striated muscle fibers. J. Physiol. (Lond.) 208: 607-644.

Alkon, D. L. (1983) Learning in a marine snail. Sci. Am. 249: 70-85.

Ashcroft, F. M., and P. R. Stanfield (1982) Calcium and potassium currents in muscle fibers of an insect (Carausius morosus). J. Phyisol. (Lond.) 323. 93-115.

Catterall, W. (1984) The molecular basis of neuronal excitability. Science 223: $653-661$

Connor, J. A., and C. F. Stevens (1971a) Inward and delayed outward membrane currents in isolated neural somata under voltage clamp. J. Physiol. (Lond.) 213: 1-19.

Connor, J. A., and C. F. Stevens (1971b) Voltage clamp studies of a transient outward membrane current in gastropod neural somata. J. Physiol. (Lond.) 213: $21-30$

Conti, F., and $E$. Neher (1980) Single channel recording of $\mathrm{K}^{+}$currents in squid axons. Nature 285: 140-143.

Crossley, A. C. (1978). The morphology and development of the Drosophila muscular system. In Genetics and Biology of Drosophila, M. Ashburner and T. R. F. Wright, eds., Vol. 2b, pp. 499-559, Academic Press, Inc., New York.

Dodge, F. A., and B. Frankenhaeuser (1959) Sodium currents in the myelinated nerve fiber of Xenopus laevis investigated with the voltage clamp technique. J. Physiol. (Lond.) 148: 188-200.

Fatt, P., and B. L. Ginsborg (1958). The ionic requirements for the production of action potentials in crustacean muscle fibers. J. Physiol. (Lond.) 142 : 516-543.

Ganetzky, B., and C. -F. Wu (1982a) Indirect suppression involving behavioral mutants with altered nerve excitability in Drosophila melanogaster. Genetics 100: 597-614.

Ganetzky, B., and C.- F. Wu (1982b) Drosophila mutants with opposing effects on nerve excitability: Genetic and spatial interactions in repetitive firing. J. Neurophysiol. 47: 501-514.

Ganetzky, B., and C. -F. Wu (1983) Neurogenetic analysis of potassium currents in Drosophila: Synergistic effects on neuromuscular transmission in double mutants. J. Neurogenet. 1: 17-28.

Ganetzky, B., and C. - - . Wu (1984) Mutations of a gene attecting potassium currents induced by transposable elements in Drosophila. Soc. Neurosci. Abstr. 10: 1090

Hagiwara, S. (1973) Ca spike. Adv. Biophys. 4: 71-102.

Hagiwara, S., and L. Byerly (1981) Calcium channel. Annu. Rev. Neurosci. 4: $69-125$.

Hagiwara, S., S. Yoshida, and M. Yoshii (1981) Transient and delayed potassium currents in the egg cell membrane of the coelenterate, Renilla koellikeri. J. Physiol. (Lond.) 318: 123-111.

Hahin, R., and D. Campbell (1983) Simple shifts in the voltage dependence 
of sodium channel gating caused by divalent cations. J. Gen. Phyisol. 82 : 785-805.

Hewitt, C. G. (1914) The House Fly, Cambridge University Press, Cambridge, England.

Hille, B. (1973) Potassium channels in myelinated nerve. Selective permeability to small cations. J. Gen. Physiol. 61: 669-686.

Hodgkin, A. L., and A. F. Huxley (1952a) the components of membrane conductance in the giant axon of Loligo. J. Physiol. (Lond.) 116: 473-496.

Hodgkin, A. L., and A. F. Huxley (1952b) The dual effect of membrane potential on sodium conductance in the giant axon of Loligo. J. Physiol. (Lond.) 116: 497-506.

Hodgkin, A. L., and A. F. Huxley (1952c) A quantitative description of membrane current and its application to conduction and excitation in nerve. J. Physiol. (Lond.) 117: 500-544.

Ikeda, K., and W. D. Kaplan (1970) Patterned neural activity of a mutant Drosophila melanogaster. Proc. Natl. Acad. Sci. U. S. A. 66: 765-772

Jan, L. Y., and Y. N. Jan (1976) Properties of the larval neuromuscular junction in Drosophila melanogaster. J. Physiol. (Lond.) 262: 215-236.

Jan, L. Y., S. Barbel, L. Timpe, C. Laffer, L. Salkoff, P. O'Farrell, and Y. N. Jan (1983) Mutating a gene for a potassium channel by hybrid dysgenesis: An approach to cloning of the Shaker locus in Drosophila. Cold Spring Harbor Symp. Quant. Biol. 48: 233-245.

Jan, Y. N., L. Y. Jan, and M. J. Dennis (1977) Two mutations of synaptic transmission in Drosophila. Proc. R. Soc. Lond. (Biol.) 198: 87-108.

Kamb, A., L. Iverson, and M. Tanouye (1984) Molecular analysis of the Shaker (Sh) gene complex in Drosophila melanogaster. Soc. Neurosci. Abstr. 10: 1089

Kandel, E. R., and J. H. Schwartz (1982) Molecular biology of learning: Modulation of transmitter release. Science 218: 433-443.

Kaplan, W. D., and W. E. Trout, III (1969) The behavior of four neurolugical mutants of Drosophila. Genetics 61: 399-409.

Meech, R. W. (1978) Calcium-dependent potassium activation in nervous tissues. Annu. Kev. Biophys. Bioeng. 7: 1-18.

Mishina, M., T. Tobimatsu, K. Imoto, K.-i. Tanaka, Y. Fujita, K. Fukuda, M. Kurasaki, H. Takahashi, Y. Morimoto, T. Hirose, S. Inayama, T. Takahashi, M. Kuno, and S. Numa (1985) Location of functional regions of acetylcholine receptor $\alpha$-subunit by site-directed mutagenesis. Nature 313: 364369.

Neher, E. (1971) Two fast transient current components during voltage clamp on snail neurons. J. Gen. Physiol. 58: 36-53.

Ogden, T. E., M. C. Citron, and R. Pierantoni (1978) The jet stream micro beveler: An inexpensive way to bevel ultrafine glass micropipettes. Science 201: 469-670.

Osborne, M. P. (1967) Supercontraction in the muscles of the blowlly larva: An ultrastructural study. J. Insect Physiol. 13: 1471-1482.

Salkoff, L. (1983a) Drosophila mutants reveal two components of fast outward current. Nature 302: 249-251.

Salkoff, L. (1983b) Genetic and voltage clamp analysis of a Drosophila potassium channel. Cold Spring Harbor Symp. Quant. Biol, 48: 221-231.

Salkoff, L., and R. Wyman (1981) Genetic modification of potassium channels in Drosophila Shaker mutants. Nature 293: 228-230.

Salkoff, L., and R. Wyman (1983) lon currents in Drosophila flight muscles. J. Physiol. (Lond.) 337: 687-708.

Serrano, E. E. (1982) Variability in molluscan neuron soma currents. Ph.D. thesis, Stanford University, Palo Alto, CA.

Siddiqi, O., and S. Benzer (1976) Neurophysiological defects in temperaturesensitive paralytic mutants of Drosophila melanogaster. Proc. Natl. Acad. Sci. U. S. A. 73: 3253-3257.

Sun, Y. A., and C. -F. Wu (1984) Voltage-dependent single-channel currents in dissociated CNS neurons of Drosophila. Soc. Neurosci. Abstr. 10: 1090

Suzuki, N., and M. Kano (1977) Development of action potential in larval muscle fibers in Drosophila melanogaster. J. Cell. Physiol. 93: 383-388.

Tanouye, M., A. Ferrus, and S. C. Fujita (1981). Abnormal action potentials associated with Shaker locus of Drosophila. Proc. Natl. Acad. Sci. U. S. A. 78: 6548-6552

Taylor, R. E., J. W. Moore, and K. S. Cole (1960) Analysis of certain errors in squid axon voltage clamp measurements. Biophys. J. 1: 161-202.

Weidmann, S. (1952) The electrical constants of Purkinje fibers. J. Physiol. (Lond.) 118: 348-360

Werman, R., F. V. McCann, and H. Grundfest (1961) Graded and all-or-none electrogenesis in arthropod muscle. I. The effect of alkali-earth cations on neuromuscular system of Romalea microptera. J. Gen. Physiol. 44: 979995

Wu, C. -F., and B. Ganetzky (1980) Genetic alteration of nerve membrane excitability in temperature-sensitive paralytic mutants of Drosophila melanogaster. Nature 286: 814-816

Wu, C. - F., and B. Ganetzky (1984) Properties of potassium channels altered by mutations of two genes in Drosophila. Biophys. J. 45: 77-78.

Wu, C. -F., B. Ganetzky, L. Y. Jan, Y.-N. Jan, and S. Benzer (1978) A Drosophila mutant with a temperature-sensitive block in nerve conduction. Proc. Natl. Acad. Sci. U. S. A. 75: 4047-4051.

Wu, C. - F., B. Ganetzky, F. Haugland, and A. -X. Liu (1983a) Potassium currents in Drosophila: Different components affected by mutations of two genes. Science ?20: 1076-1078.

Wu, C. -F., N. Suzuki, and M.-m. Poo (1983b) Dissociated neurons from normal and mutant Drosophila larval central nervous system in cell culture. J. Neurosci. 3: 18881889.

Yamamoto, D., and H. Washio (1981) Voltage clamp studies on insect skeletal muscle. II. The outward currents. J. Exp. Biol. 90: 13-22.

Yamamoto, D., J. -I. Fukanii, and H. Washio (1981) Voltage clamp studies on insect skeletal muscle. I. The inward current. J. Exp. Biol. 90: 1-12. 